\title{
The role of red and processed meat in colorectal cancer development: a perspective
}

\author{
Marije Oostindjer ${ }^{\mathrm{a}, *}$, Jan Alexander ${ }^{\mathrm{b}, 1}$, Gro V. Amdam ${ }^{\mathrm{a}, \mathrm{c}, 1}$, Grethe Andersen ${ }^{\mathrm{d}, 1}$, Nathan S. Bryan ${ }^{\mathrm{e}, 1}$, \\ Duan Chen ${ }^{\text {f,1 }}$, Denis E. Corpet ${ }^{\text {g,1 }}$, Stefaan De Smet ${ }^{\text {h,1 }}$, Lars Ove Dragsted ${ }^{\mathrm{i}, 1}$, Anna Haug ${ }^{\mathrm{j}, 1}$, Anders H. Karlsson ${ }^{\text {k,1 }}$, \\ Gijs Kleter ${ }^{1,1}$, Theo M. de Kok ${ }^{\mathrm{m}, 1}$, Bård Kulseng ${ }^{\mathrm{f}, 1}$, Andrew L. Milkowski ${ }^{\mathrm{n}, 1}$, Roy J. Martin ${ }^{\mathrm{o}, 1}$,
} Anne-Maria Pajari ${ }^{\mathrm{p}, 1}$, Jan Erik Paulsen ${ }^{\mathrm{q}, 1}$, Jana Pickova ${ }^{\mathrm{r}, 1}$, Knut Rudi ${ }^{\mathrm{a}, 1}$, Marianne Sødring ${ }^{\mathrm{q}, 1}$, Douglas L. Weed ${ }^{\mathrm{s}, 1}$, Bjørg Egelandsdal ${ }^{\mathrm{a}}$

a Department of Chemistry, Biotechnology and Food Science, Norwegian University of Life Sciences, PO Box 5003, 1432 Aas, Norway

b Norwegian Institute of Public Health, PO Box 4404 Nydalen, 0403 Oslo, Norway

c School of Life Science, Arizona State University, PO Box 874501, Tempe AZ 85287, USA

d Danish Agriculture \&' Food Council, Axelborg, Axeltorv 3, 1609 Copenhagen, Denmark

e Texas Therapeutics Institute, The University of Texas Health Science Center at Houston, 1825 Pressler Street, Houston, TX 77030, USA

${ }^{f}$ Department of Cancer Research and Molecular Medicine, Norwegian University of Science and Technology, 7489 Trondheim, Norway

${ }^{g}$ Université de Toulouse, ENVT, INRA, UMR1331 Toxalim, 23 Capelles, F-31076 Toulouse, France

${ }^{\mathrm{h}}$ Ghent University, Faculty of Bioscience Engineering, Department of Animal Production, Laboratory of Animal Nutrition and Animal Product Quality, Proefhoevestraat 10, 9090 Melle, Belgium

i Department of Nutrition, Exercise and Sports, University of Copenhagen, Frederiksberg, Denmark

j Department of Animal and Aquacultural Sciences, Norwegian University of Life Sciences, PO Box 5003, 1432 Aas, Norway

${ }^{\mathrm{k}}$ Department of Food Science, University of Copenhagen, Rolighedsvej 30, DK-1958 Frederiksberg C, Denmark

${ }^{1}$ RIKILT-Institute of Food Safety, Wageningen University and Research Centre, Wageningen, The Netherlands

m Department of Toxicogenomics, Maastricht University, PO Box 616, 6200 MD Maastricht, The Netherlands

${ }^{n}$ University of Wisconsin, Department of Animal Sciences, Meat Science E'Muscle Biology Laboratory, 1805 Linden Drive, Madison, WI 53706, USA

${ }^{\circ}$ Western Human Nutrition Research Center, Davis, 430 West Health Sciences Drive, Davis, CA 95616, USA

${ }^{\mathrm{p}}$ Department of Food and Environmental Sciences, Division of Nutrition, PO Box 66, University of Helsinki, Helsinki, Finland

q Norwegian University of Life Sciences, Department of Food Safety and Infection Biology, PO Box 8146 Dep., 0033 Oslo, Norway

${ }^{\mathrm{r}}$ Department of Food Science, Swedish University of Agricultural Sciences, PO Box 7082, 75007 Uppsala, Sweden

${ }^{s}$ DLW Consulting Services, LLC., 1302 N Oak Forest Rd., Salt Lake City, UT 84103, USA

\section{A R T I C L E I N F O}

\section{Article history:}

Received 20 December 2013

Received in revised form 14 February 2014

Accepted 17 February 2014

Available online 24 February 2014

\section{Keywords:}

Red meat

Processed meat

Colorectal cancer

Animal models

Epidemiology

Phytochemicals

\begin{abstract}
A B S T R A C T
This paper is based on a workshop held in Oslo, Norway in November 2013, in which experts discussed how to reach consensus on the healthiness of red and processed meat. Recent nutritional recommendations include reducing intake of red and processed meat to reduce cancer risk, in particular colorectal cancer (CRC). Epidemiological and mechanistic data on associations between red and processed meat intake and CRC are inconsistent and underlying mechanisms are unclear. There is a need for further studies on differences between white and red meat, between processed and whole red meat and between different types of processed meats, as potential health risks may not be the same for all products. Better biomarkers of meat intake and of cancer occurrence and updated food composition databases are required for future studies. Modifying meat composition via animal feeding and breeding, improving meat processing by alternative methods such as adding phytochemicals and improving our diets in general are strategies that need to be followed up.
\end{abstract}

(C) 2014 The Authors. Published by Elsevier Ltd. Open access under CC BY-NC-ND license.

\section{Introduction}

This perspective paper was synthesized during the workshop 'How can we approach consensus on the healthiness of red meat?', held in Oslo, Norway on 6 and 7 November 2013.

\section{Meat and health}

Meat and poultry are the primary protein source in Western omnivorous diets. Intake of beef, pork, lamb and poultry is around 220, 275, 240 and $140 \mathrm{~g} /$ day/person in the US and Australia, Spain,

\footnotetext{
* Corresponding author. Tel.: + 47 64965840, + 4722122522 (until July 1st 2014).

E-mail address: marije.oostindjer@nmbu.no (M. Oostindjer).

${ }^{1}$ Except for the corresponding and last author, all authors contributed equally to the paper and are listed alphabetically.
} 
UK and Norway, respectively (based on FAOSTAT protein intake data, $20 \%$ protein in lean meat). Trend analyses over the last decades indicate that the consumption of meat products in most European countries is relatively constant and that consumers are becoming more critical with regard to health and safety aspects of food in general, including meat products (EU Fact Sheet, 2004; Walker, Rhubart-Berg, McKenzie, Kelling, \& Lawrence, 2005). As a consequence, the market segment labeled as 'light and healthy' is indeed the main segment of meat products that showed considerable growth during the last 10-15 years (in the US: USDA ERS, 2009; in Australia: Williams \& Droulez, 2010). Consumer perception is negatively influenced by messages in the media that unhealthy diets are (among other things) characterized by high meat consumption (Schonfeldt \& Hall, 2012). This image of meat products is further influenced by reports on the potential health risks associated with the addition of preservatives such as nitrite and by the perception that meat may be associated with cancer.

Indeed, the negative publicity on meat consumption was fuelled in part by a report by the World Cancer Research Fund (World Cancer Research Fund/American Institute for Cancer Research, 2007). This expert panel report states that there is convincing scientific evidence that the consumption of red and processed meat (Box 1) is associated with an increased cancer risk, specifically colorectal cancer (CRC). The conclusions from the report have been implemented into nutritional recommendations, such as in the new Nordic Nutrition Recommendations (NNR, 2012), and the guidelines in France (Programme National Nutrition Santé, 2009) and UK (Scientific Advisory Committee on Nutrition, 2010). Such guidelines aim to optimize the intake and combination of nutrients in the general population, focusing on the whole diet with the goal of reducing non-communicable diseases such as cancer, cardiovascular diseases, obesity, diabetes and osteoporosis. The Nordic recommendation regarding processed and red meat is to switch from high fat to lean meat and to limit processed and red meat consumption to less than $500 \mathrm{~g}$ of cooked red meat or processed meat products per week.

\section{What are the types of studies used to investigate the links between red and processed meat intake and CRC?}

\subsection{Evidence from human studies}

CRC is the number one cause of cancer mortality in European nonsmokers (Ferlay et al., 2013). Preventability estimates in the USA suggest that $50 \%$ of the cases of CRC could be avoided by improving the diet (nutrition) and physical activity (World Cancer Research Fund, 2009). Yet, uncertainty exists regarding the supposed link between meat consumption and CRC. For example, meat intake could explain a major part of the variation in the incidence of CRC, and then CRC should be less common among vegetarians than among meat eaters. However, the findings on these associations are inconsistent: one study found a lower incidence of CRC for vegetarians (Fraser, 1999), another found no difference between meat eaters and vegetarians (Sanjoaquin, Appleby, Thorogood, Mann, \& Key, 2004), and yet another detected a lower incidence in the meat eaters (Key et al., 2009). Hence, the relationship seems to be complex and not only depend on the meat intake but also on the total composition of the diet. Associations may also depend on genetic or environmental backgrounds: The Sami people of Northern Europe, who are reindeer-herders and have high levels of red meat intake, have lower levels of colon cancer than reference populations from the same regions (Hassler, Sjölander, Grönberg, Johansson, \& Damber, 2008), yet an opposite effect was found for Alaska Natives (O Brown, Lanier, \& Becker, 1998). Several observational studies relating meat intake and CRC show no significant risk (Parnaud \& Corpet, 1997; Parr, Hjartaker, Lund, \& Veierod, 2013; Truswell, 2009). Several goodquality meta-analyses of cohort studies show, however, significant but weak associations between incidence of CRC and intake of both fresh red meat or processed meat (Alexander, Weed, Cushing, \& Lowe, 2011; Aune et al., 2013; Chan et al., 2011; Larsson \& Wolk 2006; Norat, Lukanova, Ferrari, \& Riboli, 2002; World Cancer Research Fund/ American Institute for Cancer Research, 2007)(Fig. 1). For example, the study by Chan et al. (2011) showed a summary relative risk for CRC of 1.17 for $100 \mathrm{~g} /$ day of fresh red meat $(95 \% \mathrm{CI}=1.05-1.31,8$ studies, 4314 cases) and 1.18 for $50 \mathrm{~g} /$ day of processed meat $(95 \% \mathrm{CI}$ $=1.10-1.28,9$ studies, 10863 cases). Another example is the study by Aune et al. (2013) in connection with updating the evidence related to the World Cancer Report Fund report of 2007, which found a summary relative risk for CRC of 1.27 (95\% CI $=1.16-1.40$ ) for 100 g-day of fresh red meat, and $1.29(95 \% \mathrm{CI}=1.10-1.53)$ for $50 \mathrm{~g} /$ day of processed meat. These associations are considered weak in epidemiological studies as the relative risk is below 2.0 and the non-linear dose response curve that was observed does not support a causal claim. It should be noted that such meta-analyses combine studies from different regions in the world, from both genders, from fresh red meat and processed meat with sometimes ambiguous classifications, from colon cancer and rectal cancer incidence, and all levels of meat intake are included in such studies. Added to these methodological problems are the following: the associations are weak in magnitude and may represent confounding by other dietary and lifestyle factors, there is heterogeneity across studies, and there are inconsistent patterns of associations across the sub-groups analyses. Indeed, evidence is available suggesting the absence of a meat related CRC risk with populations at low levels of meat intake and of general mortality (Key et al., 2009) as well as in cohorts with high levels of general mortality and different ethnicities (Ollberding, Nomura, Wilkens, Henderson, \& Kolonel, 2011). Given these uncertainties, the debate about the healthiness of red and processed meat with respect to CRC will likely continue.

Observational studies of this topic cannot fully correct for all confounding factors and are unlikely to establish a cause-and-effect relationship between meat consumption and CRC by themselves. Ideally, in order to investigate whether such a causal link exists, randomized controlled prevention trials could be carried out. However, in practice it is not feasible to conduct trials using long-term interventions with food, as participants may have problems complying with the food protocol over a longer time. Because tumor development in humans can easily take 10-20 years (Kelloff et al., 2004) and human studies are costly, animal studies are conducted to examine whether a causal relationship exists in these different species, to understand mechanisms and to find potential chemopreventive agents that can be relevant for human cancer development (Corpet \& Pierre, 2005). A way forward in human studies would be to investigate biomarkers of CRC incidence as early end points.

\subsection{Animal model studies}

Experimental animal models have been used for decades to test the effects of different diets and diet-derived compounds on colon carcinogenesis. While there are different models available, rodents are among the most-used animals for tumor biology research. In order to speed up results, animals are made more susceptible to the development of tumors in response to environmental challenges, including the diet. Increased susceptibility can be achieved through administration of a carcinogen, or selection for genetic mutations (Corpet \& Pierre, 2005).

One of the rodent models with increased susceptibility due to genetic mutations is the APCmin mouse. The tumor suppressor gene adenomateous polyposis coli (APC) is often the first gene to be mutated in the sequence of mutations leading to the development of colorectal cancer, according to Vogelstein's scheme (Kinzler \& Vogelstein, 1996) (Box 2). Germline mutations of the APC gene lead to familial adenomatous polyposis (FAP), characterized by the development of multiple colorectal adenomas (Fodde, 2002; Half, Bercovich, \& Rozen, 2009). In addition, somatic mutations of the 


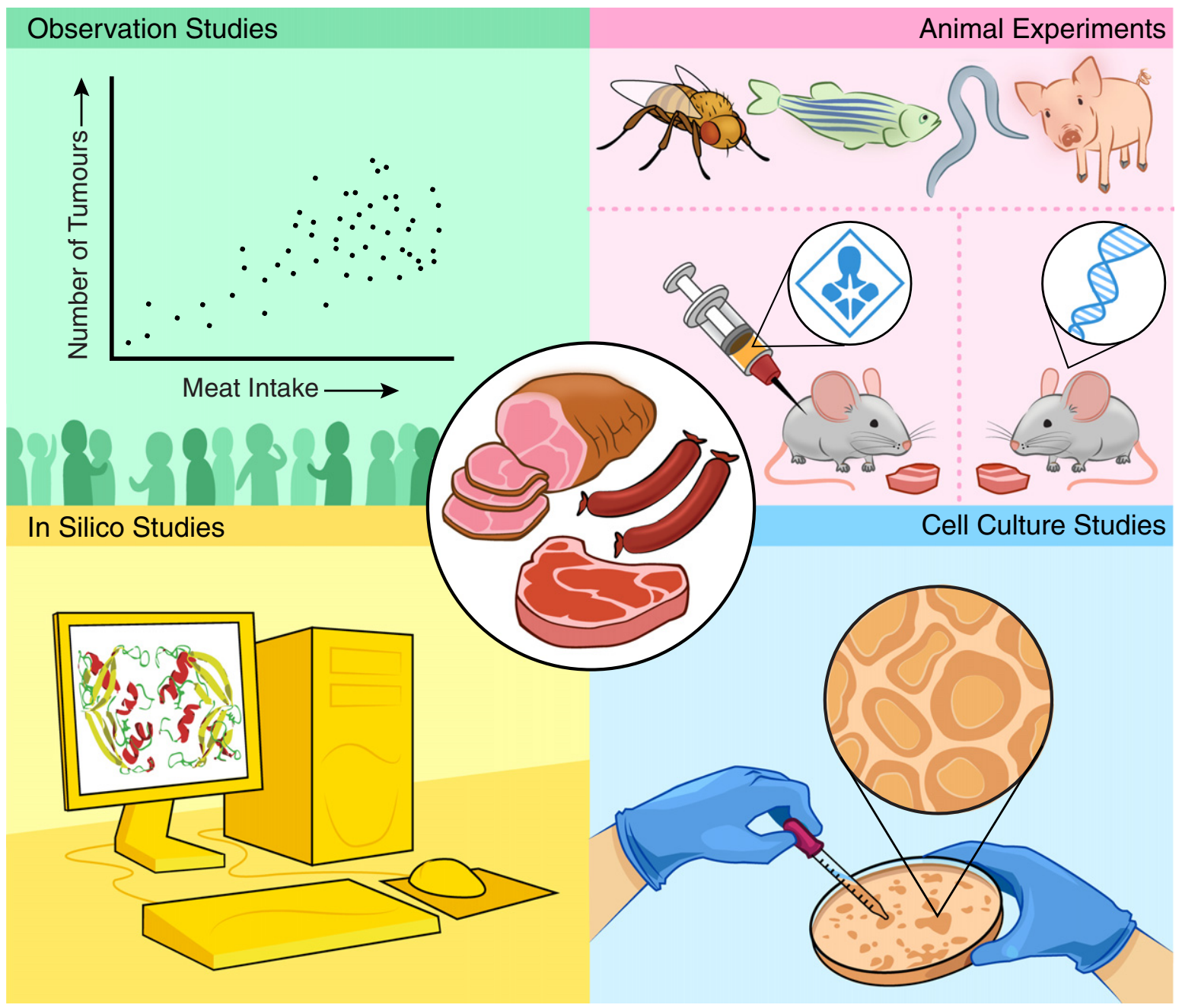

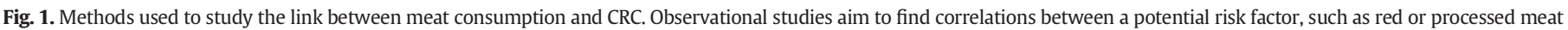

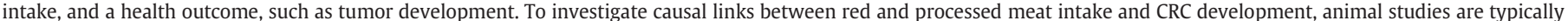

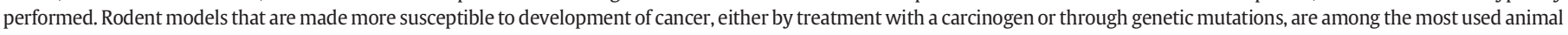

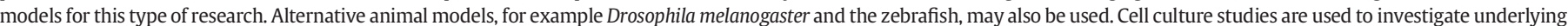

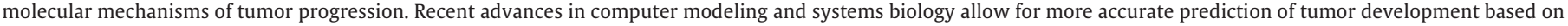
environmental and molecular factors, but it is likely that the full potential of such in silico approaches has not yet been reached.

APC gene are found in more than $85 \%$ of the sporadic colorectal cancers (Fearnhead, Britton, \& Bodmer, 2001). The APCmin mouse is a FAP model, which mainly develops adenomas in the small intestine (Fodde \& Smits, 2001; Paulsen, 2000; Su et al., 1992; Van Es, Giles, \& Clevers, 2001) but depending on the strain may also have a high incidence of adenomas in the colon as well. In FAP, murine FAP models and the majority of human sporadic colorectal cancers, tumor initiation seems to be dependent on somatic genetic events that lead to the inactivation of both APC alleles. Tumor initiation occurs when a stem cell loses its full-length APC protein (APC - /-), transforms and gives rise to a lineage of dysplastic cells, which consequently develop into early lesions (flat aberrant crypt foci, flat ACF, and mucin depleted foci, MDF; Femia, Paulsen, Dolara, Alexander, \& Caderni, 2008) and eventually into tumors. Because of its APC $+/-$ status the APCmin mouse is an excellent model for studying gene $\times$ environment interactions in Apc-driven colorectal cancer, since the model is vulnerable for environmental factors that disrupt the Apc gene (dietary carcinogens), or factors that compensate for the lost Apc function (protective factors) (Femia et al., 2008; Ølstørn, 2009; Paulsen, Namork, Steffensen, Eide, \& Alexander, 2000; Paulsen et al., 2001; Steffensen, Paulsen, Eide, \& Alexander, 1997). APCmin mice provide a close resemblance to human colon cancer pathobiology (Preston et al., 2008) and tumorigenesis is observed within a few weeks. However, screening a large number of diet-derived compounds using this model is a labor intensive and expensive task to carry out. Other genetically modified models are also available (Alexander, 2000).

Alternatively, cancer can be induced by injecting a colon-specific carcinogen, usually dimethylhydrazine, to rats and mice. Other chemicals may be used including $\mathrm{N}$-nitrosamines and heterocyclic amines. Promoting effects of food components such as meat can be examined in these models, however, testing using tumor incidence as an end-point requires groups of thirty animals for 2-300 days before tumors are formed. More affordable studies use early stages of tumorigenesis, scored in groups of ten rats given tested diet for 100 days (Caderni et al., 2003; Femia, Dolara, Luceri, Salvadori, \& Caderni, 2009). Carcinogen-treated rodents develop a large number of aberrant crypts in the colon (Corpet \& Pierre, 2005), but only a small subgroup of these early lesions develop into adenomas and carcinomas. Early lesions like MDF and flat ACF have been identified in carcinogen-treated rodents, APCmin mice, as well as in colon cancer patients (Caderni et al., 2003; Femia et al., 2008). As observed during CRC development, the crypts of MDF and flat ACF are characterized by severe dysplasia and altered APC function that leads to increased Wnt-signaling into the cell, which results in rapid cell division. In normally differentiated crypts cells the WNT-signal is down-regulated by intact APC. 
Box 1

Red and processed meats.

The definitions of red and white meat vary. Generally, the term white refers to meats pale before cooked (poultry, fish; sometimes also pork, Williams, 2007), and red meats if red before cooked (beef, lamb; sometimes also pork, McAfee et al., 2010). Occasionally, red meat is said to be from mammals, white meat from other animals, and game is considered a third category. Birds with a high concentration of dark meat, such as ducks and geese, are now and then categorized as red meat, even if their meat is pale pre-cooking. Meats are sometimes divided into red or white due to their flavor: white meats tend to be more bland (chicken, pork), and red meats have a more intense flavor. Compared to white meats, red meats are red due to higher content of the protein myoglobin, creating the distinctive dark color, although there is no objective threshold of the heme level that is used to make the distinction between white and red meat. The above described ambiguous categorization can become a problem for consumers when they learn about the cancer risk associated with red meat, as they may not know which specific products are referred to. A similar problem exists for processed meats as processed meats can contain different raw materials including potential protective factors and there is a whole scale of production methods that may pose a large or small risk for the CRC. A recently suggested definition of processed meat includes meat that undergoes various kinds of preservation, such as curing, smoking or drying, but can also include meat that has undergone treatment to alter the flavor or improve the quality (Alexander et al., 2010). Meats processed by salting or smoking and meats prepared by frying or grilling are particularly studied for their alleged effects on cancer risk.

Experimental studies published before 2001 failed to show an excess of colon tumors in rodents given red meat compared with casein- or soy-fed controls (Parnaud, Peiffer, Tache, \& Corpet, 1998; Mutanen, Pajari, \& Oikarinen, 2000). More recent studies show, however, that beef meat promotes colon carcinogenesis in carcinogen-treated rats, which is consistent with epidemiological data (Chan et al., 2011), provided that the animal feed contains little calcium. This effect of meat is mimicked by an equivalent dose of heme iron, suggesting heme iron alone explains cancer promotion by red meat (Pierre, Freeman, Tache, Van der Meer, \& Corpet, 2004). Heme inducible peroxidation end products are cytotoxic to normal colonic cells, but APCmutated cells continue to grow. This path explains meat-induced promotion of tumorigenesis, via selection of the mutated precancer cells in the colon mucosa (Pierre et al., 2004). Several whole foods promote carcinogenesis in rats: hot-dog, cooked ham, blood sausage (not cured), and several workshop-cured meat products (Pierre et al., 2004; Santarelli et al., 2010, 2013). The effect of meat on suspected cancer initiators and promoters can be measured in the feces as products of nitrosation and lipoperoxidation (Pierre, Santarelli, Tache, Gueraud, \& Corpet, 2008; Pierre, Tache, Petit, Van der Meer, \& Corpet, 2003; Santarelli et al., 2013). The same biomarkers are raised in volunteers given cured meat (Joosen et al., 2009; Kuhnle et al., 2007; Pierre et al., 2013). These studies show that meat and components of meat can stimulate CRC development in sensitive animal models fed semipurified diets containing no vegetables or cereal fibers (Box 3).

\subsection{Use of in vitro models}

Animal models have an endpoint (cancer or mortality) but it is difficult to track tumor progression while the animal is still alive. In order to investigate the underlying molecular mechanisms of
Box 2

What is colorectal cancer?

Colorectal cancer (CRC) is the third most common cancer worldwide accounting for approximately 1.2 million new cases and over 600000 deaths in 2008. Sporadic CRC is more commonly seen in developed regions, with the highest rates found in Australia/New Zealand, North America and Western Europe, and remains relatively uncommon in less developed regions including most of Africa and South-Central Asia. CRC incidence rates are markedly higher in men than in women, and this cancer becomes increasingly more common with age (American Cancer Society, 2011; Ferlay et al., 2013). CRC develops as a result of multiple genetic and epigenetic changes which cause normal intestinal epithelium to transform into colon carcinoma via the activation of oncogenes and inactivation of tumor suppressor genes, in a process known as the adenomacarcinoma sequence (Kinzler \& Vogelstein, 1996; Leslie, Carey, Pratt, \& Steele, 2002). Most cases of colorectal cancer appear to be caused by somatic mutations, but a small number of cases are the result of germline mutations. The two most common inherited colorectal cancer syndromes are Hereditary Nonpolyposis Colorectal Cancer (HNPCC), caused by germline mutations in DNA mismatch repair (MMR) genes, and Familial Adenomatous Polyposis (FAP), caused by germline mutations in the tumorsuppressor gene adenomatous polyposis coli (APC) (Kinzler \& Vogelstein, 1996). Colorectal carcinogenesis is often explained by three distinct pathways; chromosomal instability (CIN), microsatellite instability (MSI), and $\mathrm{CpG}$ island methylator phenotype (CIMP). The CIN pathway, also known as the gatekeeper pathway, accounts for the majority of sporadic and FAP colorectal cancers and is characterized by chromosomal abnormalities and loss of heterozygosity. The MSI pathway, also known as the caretaker pathway, is involved in $10-15 \%$ of sporadic colorectal cancers, and in most HNPCC, and is characterized by instability at the nucleotide level caused by abnormalities in DNA mismatch repair genes. The third pathway, CIMP, is considered to be an epigenetic pathway, where tumor suppressor genes are silenced by hypermethylation of $\mathrm{CpG}$ islands in the promoter region (Kinzler \& Vogelstein, 1997; Migliore, Migheli, Spisni, \& Coppede, 2011; Toyota et al., 1999).

tumor biology, established cancer cell lines such as the immortalized mouse fibroblast cell lines and human HaCaT cell line are used (for example Araújo, Gonçalves, \& Martel, 2011; Dommels et al., 2003; Glei et al., 2002; Hague, Butt, \& Paraskeva, 1996; McCanna et al., 2007). These cell lines are typically grown on practically flat two-dimensional (2D) culture dishes. However, cells grown in such a way lack many aspects of cells in whole body context. They often differ in morphology and in cell-cell and cell-matrix contacts which limit their ability to predict a compound's true effects on tumorigenesis (Elamin et al., 2012; Tsunoda et al., 2010). Threedimensional (3D) cell line cultures offer a new exciting opportunity to mimic conditions in vivo more closely than traditional 2D cell cultures and thus bridge the gap between 2D cell culture and animal models (Yamada \& Cukierman, 2007). The advantage of 3D over 2D cell cultures is that 3D provides information on tissue organization and architecture and allows observation of changes in tissue organization which can be used as predictors for cancer development (Carothers, Melstrom, Mueller, Weyant, \& Bertagnolli, 2001; Hughes et al., 2002; Kroboth et al., 2007; Watanabe et al., 2004; Wodarz \& Näthke, 2007). Compared to animal studies in vivo, experiments with cell cultures provide results in a shorter time and are therefore more suitable to carry out screening of large number of compounds and for 
investigating the mechanisms underlying cancer development. However, interactions between different tissues cannot be studied in cell cultures, and there is no direct cancer-related endpoint such as tumor development or mortality. Hence, in vitro models can currently only support in vivo models for determining the effect of food consumption on health outcomes.

\subsection{What is the ideal animal model for studying the link between red meat intake and health?}

There is not a single ideal animal model currently available. However, available models can be useful depending on the question, after critical evaluation of how and what is being induced, and how the results tell a story related to human health. In many cases the choice of model is a compromise between biological and practical motivations. Biological motivations include high sensitivity to the treatment, high specificity and a similarity in digestive system and underlying molecular mechanisms of tumor progression to humans. Practical motivations for a model include being small, cheap, easy to handle, easily available, genetically stable, having a short generation time and a quick development of cancer. For these reasons, rodent models with carcinogenic induction or genetic susceptibility to cancer are most often used for tumor biology research. Humanized mice (by introduction of human genes or microbiota), mouse genetic reference populations, and inbred and outbred rodent strains all could be useful in understanding mechanisms underlying diet mediated gut health and cancer development. Other relevant but less practical models include pigs (similar digestive system to humans, but expensive) and primates (expensive and ethical issues). Drosophila C. elegans and zebra fish are easy to breed and low in maintenance cost, but have a digestive system that is quite different from humans. However, APC mutants are now available in Drosophila (Wang et al. 2013) and zebrafish (Goessling et al., 2008), making it possible to study the relationship between diet and cancer development that is relevant for human APC-mediated tumorgenesis in these animals. Recent advances in artificial intelligence, computer simulations and systems biology have resulted in an increase in in silico studies of cancer development, including predictions of tumor growth and regression based on established knowledge about the chemical composition of the environment and metabolic processes in the gut (for examples of recent advances see Shin et al., 2013; Tian et al., 2013). This field develops rapidly and it is likely that the full potential for such approaches has not yet been reached. Until then, short-term feeding studies in humans are preferred assuming that good biomarkers of health can be measured.

\section{How do we think meat consumption is related to CRC?}

\subsection{N-Nitroso compounds}

Nitrate and nitrite have long been part of the human diet as nutrients in vegetables and as part of food preservation systems. Nitrate impurities in salt used in the drying of meat in ancient times caused a pink color that signaled reduced spoilage during storage and increased food safety for those items (Pegg \& Shahidi, 2000a). We now understand that nitrite is the curative agent and not nitrate. Nitrite limits growth of pathogenic microbes, controls oxidation and rancidity when added above certain thresholds and the pink color it causes is still preferred by consumers in modern times (Pegg \& Shahidi, 2000b).

The biochemical mechanisms of curing meat that involve chemical reduction of nitrate to nitrite and nitric oxide (NO) and the formation of nitroso heme pigments are now understood. A reaction between nitrogen oxides $\left(\mathrm{NO}_{2}, \mathrm{~N}_{2} \mathrm{O}_{3}, \mathrm{~N}_{2} \mathrm{O}_{4}\right.$ and others) and secondary amines (e.g. the free amino acid proline is a secondary amine) in the stomach results in N-nitroso Compounds (NOC) (Pegg \& Shahidi, 2000c)
(Fig. 2). High temperatures during for example frying can enhance the formation of NOC (Pegg \& Shahidi, 2000b). NOC can be found in normal human feces, urine and saliva, and it has been suggested that this is due to in vivo nitrosation of ingested secondary and tertiary amines (Kakizoe et al., 1979). This process may be further catalyzed by the presence of heme iron, which is also present in processed meat (Cross, Pollock, \& Bingham, 2003; Vermeer, Pachen, Dallinga, Kleinjans, \& van Maanen, 1998). Recently, human studies have demonstrated that indeed under normal dietary conditions urinary markers of exposure to $\mathrm{N}$-nitroso compounds are associated with micronucleus frequencies, a validated marker of carcinogenic risk, as well as with gene expression changes that are involved in cancer development (Hebels, Jennen, et al., 2011). Similar gene expression changes were also found in colonic biopsy material after a human intervention study with red meat (Hebels, Sveje, et al., 2011; Hebels et al., 2012).

Understanding the formation of nitrosamines after nitrite ingestion sparked intense basic research into meat curing, nitrosamine formation in cured meats and safety implications (Sindelar \& Milkowski, 2012). Meat processors have modified curing practices to reduce the use of sodium nitrite by largely abandoning the use of sodium nitrate and incorporating ascorbate or erythorbate into formulations to accelerate curing. These curing accelerators also have the benefit of being effective nitrosamine inhibitors (Tannenbaum, Wishnok, \& Leaf, 1991). Regulatory reviews in the early 1980 's also resulted in new limits on the use of nitrite and nitrate in meat curing which are still in effect today (EU Directive 2006/52/EC, 2006/52/EC). The ultimate result has been an overall decrease in residual nitrite content in cured meat products to approximately $10 \mathrm{mg} / \mathrm{kg}$ (10 ppm) for most products currently in the market place (Nunez De Gonzalez et al., 2012).

The controversy around nitrite waned after regulations were changed in the 1980s in the US and following a publication of the National Toxicology Program study involving lifetime feeding of multiple high levels of nitrite to rats and mice and examination of all body tissues for histological abnormalities (NTP, 2001). That "gold standard" toxicology study confirmed the safety of nitrite exposure at levels found in cured meats. However, the issue has been revived because of epidemiological reports (Cross et al., 2010) hypothesizing that nitrite in cured processed meats is an underlying reason for associations between processed meat consumption and cancer. Additionally, in 2006 the International Agency for Research in Cancer (IARC), part of the World Health Organization, convened a panel to evaluate nitrate and nitrite safety with respect to carcinogenicity. The panel classified "ingested nitrate or nitrite under conditions that result in endogenous nitrosation is probably carcinogenic to humans (Group 2A)" (IARC, 2010). Meat processing is largely based on the use of nitrite and/or nitrate. The recommendation in 2007 of the World Cancer Research Fund to avoid processed meat intake because of the associated epidemiological risk of CRC further added to the negative perceptions about nitrite.

While there is no doubt that both NO metabolites and secondary amines are available in the digestive system, or that NOC have the ability to promote cancer development, it is questioned whether direct formation of NOC occurs in the digestive system from eating nitrite and/or nitrate containing foods, and if these resulting NOC induce carcinogenesis. Nitrite and nitrate have important nutritional and biological functions due to reduction to NO (Bryan \& Loscalzo, 2011). NO has important physiological functions as a cellular signaling molecule, vasodilator and neurotransmitter (Bugiardini, Manfrini, Pizzi, Fontana, \& Morgagni, 2004; Halcox et al., 2002; Lerman \& Zeiher, 2005; Schächinger, Britten, \& Zeihe, 2000). Levels of endogenous NO decline with aging or due to metabolic dysfunctions and nitrite and nitrate derived from food sources or when administered in a clinical setting for specific diseases have been shown to restore NO homeostasis (Bryan et al., 2007; Carlström et al., 2010; Celermajer et al., 1994; Davignon \& Ganz, 2004; Egashira et al., 1993; Gerhard, Roddy, 
Creager, \& Creager, 1996; Lundberg, Weitzberg, \& Gladwin, 2008; Taddei, Virdis, Ghiadoni, Sudano, \& Salvetti, 2001). Dietary nitrite and nitrate have been shown to protect against ischemic heart injury, prevent vascular inflammation and improve exercise performance and could, within limits, be considered indispensable nutrients (Bryan et al., 2007; Carlström et al., 2011; Kleinbongard et al., 2006; Rassaf et al., 2007). While there are upper limits to nitrite and nitrate consumption, there is a high endogenous production of nitrite $(5.18 \mathrm{mg}$ nitrite per day, one hot dog of $50 \mathrm{~g}$ would provide $0.026 \mathrm{mg}$ nitrite and $4.88 \mathrm{mg}$ nitrate; Milkowski, 2011). Vegetables such as celery, radishes, beets and spinach, which have high levels of nitrate that can be metabolized into nitrite by oral bacteria (Hord, Tang, \& Bryan, 2009), can provide much more nitrite per portion than meat (a spinach salad of $125 \mathrm{~g}$ can provide $881 \mathrm{mg}$ nitrate). The risk regarding nitrite added to meat compared to endogenous nitrite formed from nitrate following vegetable consumption may thus be relatively small, although interactions with compounds specifically associated with meat such as heme iron need not to be forgotten. With some studies demonstrating a protective effect of nitrite in animal models of colitis, it becomes clear that there is a need to better understand nitrite metabolism and its impact on health (Ohtake et al., 2010).

While these new discoveries concerning NO physiology and the metabolic interrelationships among NO, nitrite and nitrate challenge the hypotheses that nitrite has significant carcinogenic effects in humans, the debate is still active. To address the remaining questions, critical thinking that recognizes the strengths and weaknesses of the research studies used to support opinions about the safety of cured processed meats is now needed.

\subsection{Heme iron and reactive oxygen species}

Heme iron has been implicated in intestinal cancer risk, either in combination with nitrite or alone (Joosen et al., 2009). Red meat generally contains both more heme iron and free iron than other fresh meat or fish, and heme iron is largely responsible for the color of red meat. Heme may catalyze the formation of carcinogenic N-nitroso compounds in rat models (Bastide, Pierre, \& Corpet, 2011). Heme iron also promotes carcinogenesis through increased cell proliferation in the mouse mucosa by inducing lipid oxidation (IJssennagger et al., 2013). Hemin (protoporphyrin IX with ferric iron bound to chloride) is normally absorbed in the digestive system through heme transporter proteins (Latunde-Dada, Simpson, \& McKie, 2006). However, not all of the hemin is absorbed when hemin ingestion is high, which results in hemin being present in the digestive system and the feces. Hemin is highly catalytic and can stimulate formation of reactive oxygen species when polyunsaturated fatty acids are present, such as those found in the cell membranes below the mucus layer or those accompanying bile salts (Ishikawa, Tamaki, Ohata, Arihara, \& Itoh, 2010; Lee, Kim, Kang, \& $\mathrm{Kim}, 2006)$. The reactive oxygen species have been implicated in DNA damage in many studies, and have the ability to disrupt normal cell proliferation of the gut epithelial cells, resulting in an increased risk in cancer when the damage is not repaired. Reactive oxygen species are normally formed in vivo and endogenous mechanisms are in place to reduce and repair the damage (Perše, 2013). In addition, a balanced diet including vegetables and fruits may contain enough antioxidants to 'trap' reactive oxygen species before they cause damage to the DNA (Perše, 2013; Rodriguez-Ramiro, Martin, Ramos, Bravo, \& Goya, 2011). If the diet is unbalanced due to a high intake of meat, such protective mechanisms may not be sufficient to protect the colon from DNA damage caused by heme-related reactive oxygen species. The predominant role of heme in the generation of damaging reactive oxygen species as a basis for increasing the (processed) meat related risk increase of CRC can be questioned, however. Indeed, the small differences between pig and poultry meat iron contents (see e.g. Lombardi-Boccia, MartinezDominguez, \& Aguzzi, 2002) do not seem large enough to account for the consistent absence of a carcinogenic effect of chicken consumption in contrast to beef and pork consumption. The cell surface sialic acid $\mathrm{N}$-glycolylneuraminic acid (Neu5Gc), a specific abundant component of red meat other than heme, low or absent in poultry and fish is another candidate for induction of reactive oxygen species (Byres et al., 2008). It has been suggested indeed that humans produce circulating antiNeu5Gc antibodies leading to local chronic inflammation and a propensity to develop diet-related carcinomas (Hedlund, Padler-Karavani, Varki, \& Varki, 2008). The consistent absence of a carcinogenic effect of poultry and fish consumption may thus relate to the near absence of Neu5Gc in these foods.

\subsection{Mediating factors: abnormal gut functioning and the role of gut bacteria}

In a normal state, the gut (lower intestinal tract) functions as a barrier between the body and external influences, allowing nutrients to be absorbed by the body and keeping pathogens out of the blood stream. To facilitate this balance, complex communication occurs between the gut, the brain and the immune system (Cryan \& Dinan, 2012). A large share of this communication is related to energy homeostasis, and includes signals related to blood sugar, taste, gut stretching and hormones excreted to initiate or terminate meals, extending to other organs as well (Field, Chaudri, \& Bloom, 2010). The communication between the brain and the gut is not just crucial for energy homeostasis but also for general well-being. Disruptions of the system, such as chronic stress, can result in an over-activation of the immune system, which has effects on the gut barrier function, the bacteria in the gut and through these peripheral effects even on mood (Cryan \& Dinan, 2012). A key-player in the communication between the gut and the brain, the vagal nerve has been implicated in the development of cancers. In mouse models of gastric cancer induced by genetic mutations or a carcinogenic (N-methyl-N-nitrosourea), vagotomy (disruption of the nervus vagus signaling by surgery) markedly reduced tumor incidence and progression (Kodama et al., 2012). Vagotomy was associated with inhibition of Wnt signaling and downregulation of stem/progenitor cell markers. Whether the vagal nerve plays a role in the development of CRC in the presence or absence of red meat is currently unknown. It is likely that the vagal nerve is of some importance as it plays a considerable role in chronic pathological inflammation of the gut, which in turn increases the risk for CRC.

Low level inflammation, in which there is a balance between proand anti-inflammatory factors, is important for gut health, as it allows the immune system to be activated when pathogens are present, Pathological inflammation on the other hand is categorized by a high activation of pro-inflammatory cytokines, which are pro-oxidants and can damage tissue and DNA (Jaiswal, LaRusso, Burgart, \& Gores, 2000), as well as by activation of NF- $\kappa B$ and members of the TNF cytokine family (Eigler, Sinha, Hartmann, \& Endres, 1997; Tak \& Firestein, 2001). Dimers of such cytokines can increase the transcription of tumor growth promoting genes (Fantini \& Pallone, 2008). Chronic inflammation may also be related to imbalanced diets where the intake of omega -6 polyunsaturated fatty acids is much higher than the intake of omega -3 polyunsaturated fatty acids. Both types of fatty acids compete for the same enzymes; hence it is the ratio that is implicated in determining whether there is a pro-inflammatory state (high $\mathrm{n}-6$, low $\mathrm{n}-3$ ) or an anti-inflammatory state (low $\mathrm{n}-6$, high $n-3)$. A high level of $n-3$ fatty acids has been linked to lower cell proliferation, increased apoptosis and possible limited tumor angiogenesis (Larsson, Kumlin, Ingelman-Sundberg, \& Wolk, 2004). However, it needs to be noted that a link between intake of $n-3$ fatty acids and reduced cancer risk is much clearer from short-term in vitro and in vivo experimental studies than from epidemiological data (Riediger, Othman, Suh, \& Moghadasian, 2009).

The bacteria in the gut are an important mediator for the relationship between food and (gut) health, and may play a role in both 


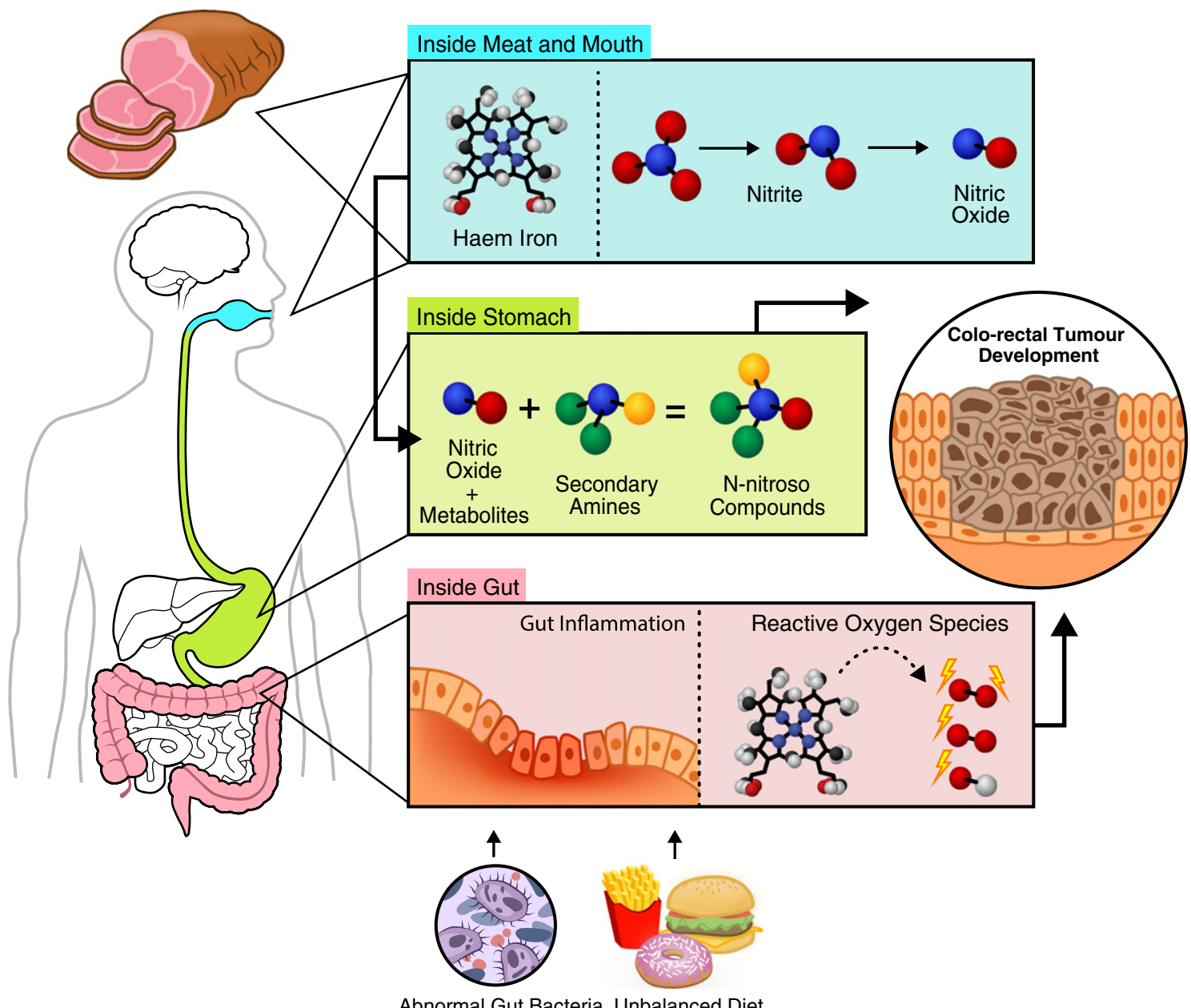

Abnormal Gut Bacteria Unbalanced Diet

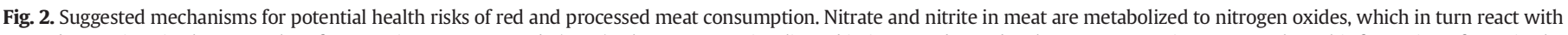

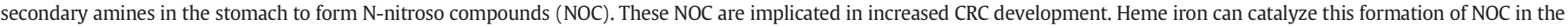

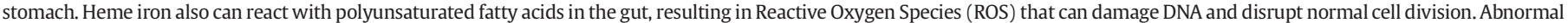
gut bacteria and an unbalanced diet are also implicated in a higher risk for CRC development through an increase in gut inflammation.

promotion of and protection against the CRC development in response to red meat. Abnormal gut fermentation has been shown to be linked to both dietary obesity and cancer (Nasser, Bibi, Alqahtani, Chaudhary, Azhar, Kamal, \& Yasir, 2013; Serban, 2013). There is new evidence that unique patterns of gut microbiota communities and their fermentation products create either a toxic or a healthy gut environment (Azcárate-Peril, Sikes, \& Bruno-Bárcena, 2011; Magrone \& Jirillo, 2013). Fecal analyses of colorectal cancer patients have shown shifts in composition of the gut bacteria, with less bacteria that produce the short chain fatty acid butyrate, and more potentially harmful bacteria such as Fusobacterium nucleatum, Rhodopseudomonas faecalis, Bacteroides vulgatus and Enterococcus faecalis, the latter being a superoxide producer that may damage epithelial DNA (Vipperla \& O'Keefe, 2012). Such pathogenic bacteria can impair gut barrier function and negatively affect gut peptides and host metabolism. A recent meta-analysis links Helicobacter pylori infection to a modest increased risk for CRC (Rokkas et al., 2013), although the molecular mechanisms responsible are unknown. It is interesting to note that obesity can be a risk factor for $H$. pylori infection and it has been hypothesized that this may provide a link for the higher incidence of certain cancers in the obese population (Arslan, Atilgan, \& Yavaşoğlu, 2009). In stressful situations the species diversity can decrease and the abundance of pathogenic bacteria that produce cytotoxic and mutagenic compounds such as hydrogen sulfide and secondary bile acids increases.
An increase in abundance of hydrogen sulfide and secondary bile acid producing bacteria is also associated with a high dietary fat intake (Vipperla \& O'Keefe, 2012). Red meat, depending on the cut and origin of the meat, may contain more fat than white meat, and the fat content in red meat is implicated as a possible risk factor for colorectal cancer through a shift in microbiota composition. Sulfate producing bacteria grow in response to a high fat diet and produce hydrogen sulfide, which is considered harmful for the gut epithelium in general, and specifically can damage the DNA through production of free radicals (Hildebrandt et al., 2009). In addition, high intake of dietary fat can increase the abundance of colonic primary bile acids and their transformation to cytotoxic, mutagenic and anti-apoptotic secondary bile acids. The epithelial damage can result in an over activation of transcription factors linked to inflammation such as NF-kB that may promote tumor cell proliferation (Jia et al., 2013). The exact role of the gut microbiota in the link between meat and health is not clear, but research thus far shows that there are several pathways through which the gut microbiota could play a role.

\subsection{Eating too much of an unbalanced diet}

Obesity has increased dramatically in the world during the last 20 years both in developed and developing countries (WHO Obesity and overweight fact sheet, 2013). The cause of obesity is due to changes in the environment, including high food availability and energy density 
and reduced need for physical activity (Hill, Wyatt, Reed, \& Peters, 2003), but also less obvious changes such as less time spent outside of the thermo-neutral zone are implicated in the increase in obesity (Moellering \& Smith, 2012). From an evolutionary standpoint, having a fat storage is advantageous for times of food scarcity and the body tries to defend a high weight set point (Bellisari, 2008, but also see Speakman, 2007, 2008). However, the increase in body weight has serious consequences for health. Diabetes and heart disease are among the highest prevalent and well-known disorders related to obesity, but there is also strong support for a causal link between being overweight and some forms of cancer, including colon cancer (1.5-2.4 fold increase in risk, Moore et al., 2004). Chronic inflammation, altered gut microbiota and high levels of adipokines and insulin-like growth factor-1 are implicated in the mechanism underlying the link between obesity and cancer (Calle \& Kaaks, 2004; Musso et al. 2010).

The increase in obesity is partly accompanied by an increased intake of an unbalanced diet. High sugar intake, particularly fructose from corn syrup and sugary drinks, less fibers, less calcium, and fewer vegetables are part of this unbalanced diet (NNR, 2012). Fat consumption is high although it has reduced in recent years, while protein intake has been quite stable for the past two decades (FAOSTAT, 2012). A high protein intake, including meat and dairy protein, is associated with weight loss or at least improved weight maintenance (Westerterp-Plantenga, Nieuwenhuizen, Tome, Soenen, \& Westerterp, 2009). Lean meat provides a high level of satiety (white bread satiety index: $100 \%$, beef: $176 \%$, boiled warm potatoes: 323\%; Holt, Miller, Petocz, \& Farmakalidis, 1995), and may thus contribute to prevention of obesity. Yet, the association between red meat, obesity and cancer may be observed due to confounding dietary factors: individuals consuming a lot of red and processed meat may often also consume more energy rich food products such as sugary drinks and sugar-rich condiments, drink more alcohol, eat less vegetables, take less vitamins and are less physically active (Alexander, 2013). In order to understand this complex interaction between the different components of the diet, it is important that we can measure the physiological consequences of the whole diet, through advances in techniques such as metabolomics.

\section{What may protect the colon from cancer?}

\subsection{Improving the bacteria in the gut}

The identification of bacteria that confer a health benefit to humans has proven difficult. The first and most obvious reason could be that there is no such thing as beneficial bacteria. The most well-studied host/bacteria interaction that rejects the idea that bacteria are not beneficial for health, is the Aphid and Buchnera symbiosis. Buchnera provides essential amino acids to the Aphid, which in return provides nutrients to the bacterium (Lai, Baumann, \& Baumann, 1994). For humans evidence for positive host/bacterial interactions comes from the development and evolution of the colon, which hosts a large bacterial population $\left(1 * 10^{10-12}\right.$ bacteria). The colon may never have evolved in this way if there was not some benefit for both the host (obtain more energy and essential nutrients from food due to fermentation by bacteria) and for the bacteria (nutrition for bacteria, Dethlefsen, McFall-Ngai, \& Relmen, 2007). The complexity, however, with more than 1000 bacterial species and 3000000 genes, makes this system tremendously difficult to understand (Arumugam et al., 2011). Not only are there large individual variations between humans; but also are there certain developmental windows of opportunities for beneficial interactions (Rudi, Storrø, Øien, \& Johnsen, 2012). Furthermore, the potential services provided by the bacteria are both complex and redundant. Despite the complexity it has recently been proven that it is possible to restore a normal gut immunological function by a mixture of 17 gut bacteria (probiotics) (Atarashi et al., 2013).

Not only probiotics can modify the composition of the gut bacteria; but also prebiotics (dietary fibers that can be fermented by the bacteria, such as resistant starch) have the ability to change the type of bacteria present in the colon, and the metabolites they produce. Improving gut fermentation may improve gut barrier function and reduce chronic inflammation of the gut (Keenan et al., 2012) and may protect against red meat-induced colonic DNA damage (Toden, Bird, Topping, \& Conlon, 2006). The enhancement of butyrate producing bacteria has also been shown to reduce cancer risk in animal models (Scharlau et al., 2009). While there has been an explosion of efforts to characterize gut microbial population in healthy and disease states, there is a need to look further than just the type of species that is present in the gut, and instead focus on understanding functional significance of microbiota changes. For example, increased abundance of mucin-degrading bacteria is associated with health, but the functional significance of this increase in mucin degradation is unknown. It is suggested that while these bacteria degrade the mucus layer for their nutrition, they are also considered probiotics that may limit the abundance of pathogens at the mucus layer through competition for binding sites and mucus flushing (Derrien et al., 2010). In addition, there is a need for further application of metabolomics to understand the role of gut bacteria and their fermentation products on health, including the identification of novel fermentation products and their bioactivity. Bioactivity measures will require novel animal and cell models of gut fermentation and host physiology markers that predict health outcomes. It is unlikely that there is one optimal set of gut bacteria that will prevent everyone from getting colon cancer, as there are large individual differences in current gut microbiota, genes, physiology and the external environment. Yet, understanding the role of the gut microbiota in maintaining gut health, including reducing CRC risk, may provide the food industry with an opportunity to develop foods for optimal gut fermentation for a healthier population, and academia to develop targeted solutions for individuals having an increased risk for development of CRC.

\subsection{Phytochemicals for gut health and as nitrite replacers}

Due to the debate regarding nitrite, the meat processing industry should take a proactive role and explore innovative technological solutions that allow for the reduction or replacement of nitrite without hampering microbiological food safety and loss of sensory quality, particularly taste and color. One example out of several initiatives is the PHYTOME project, which aims to develop new meat processing technologies that allow production of innovative meat products that have low or no nitrite and that contribute to improved human health (www.PHYTOME.eu). This will be achieved by introducing carefully selected mixtures of biologically active compounds originating from natural plant extracts. The active compounds, referred to as phytochemicals, are found in a wide range of vegetables and fruits and that are known to have beneficial health effects (Akesson \& Mercke, 2005). These compounds also possess antimicrobial activity and may therefore contribute to microbiological safety of the product (de Oliveira, Stamford, Neto, \& de Souza, 2010). Most importantly, they are known to reduce the formation of nitrosamines in the human body when consumed simultaneously with meat products (Chung, Lim, \& Lee, 2013). Some phytochemicals are also known to protect the gut from the induction of for instance oxidative genetic damage by other dietary factors and thus adverse health effects (Bartsch \& Frank, 1996; De Kok, van Breda, \& Briedé, 2012; de Kok, van Breda, \& Manson, 2008). Although many different mechanisms behind the preventive action of various classes of phytochemicals have been reported in the literature (Shu, Cheung, Khor, Chen, \& Kong, 2010), the most effective compounds in counteracting the damage induced by nitrosamines have not yet been identified. Furthermore, different types of phytochemicals can be more or less susceptible to degradation during processing. This implies that the effect of different treatments applied in the manufacturing of different meat products will have 
to be evaluated and optimized to have maximal recovery of the phytochemicals in the final product. Eventually, these products will be evaluated in a human dietary intervention study, by assessment of the impact on the endogenous formation of $\mathrm{N}$-nitroso compounds and the induction of genetic damage and gene expression changes in the colon.

\subsection{It's not just meat on the plate}

A meal is often more than just meat: fruit and vegetables, bread, pasta, rice, potatoes, fish and dairy are typical food groups that are consumed in addition to the meat. Some elements of these food groups are thought to negate potentially harmful effects of red meat consumption (but see also Box 4).

Calcium from, for example, dairy products is one compound that may have protective effects against cytotoxicity and colon cancer, for which various mechanisms that can act in parallel have been postulated. A mechanism that accounts for the protective action of calcium against meat-consumption-related effects on the colon is that calcium salts can chelate heme iron in vitro and in vivo (Allam et al., 2011; Pierre et al., 2008), making it unreactive in the gut, and the chelated heme iron is eventually excreted in the feces. Rats consuming calcium show full suppression of the carcinogenesis promoting effects of meat and heme iron diets (Pierre et al., 2003, 2008; Santarelli et al., 2013). In human volunteers calcium carbonate supplements can normalize fecal biomarkers of nitrosation and lipoperoxidation (Pierre et al., 2013).

Fiber-rich fruit and vegetables, as well as whole grain bread, pasta and rice, provide fibers that can be fermented in the gut and may change the gut environment to a healthier environment (Keenan et al., 2012). Fruits and vegetables also provide phytochemicals and vitamins such as vitamin E, folate and isothiocyanate that may have help to prevent the development of CRC by their function as antioxidants in prevention of peroxidation and/or nitrosation and by induction of defense mechanisms in the human colon (Van Breda et al., 2004). Resveratrol, found in red wine, is another phytochemical that is implicated to be protective, particularly in inhibition of metastasis (Shu et al., 2010). Fish intake may also contribute to a healthier colon by providing $n-3$ polyunsaturated fatty acids that have anti-inflammatory effects (Larsson et al., 2004).

The preparation of the meat can also have an impact. Seasonings such as garlic (containing selenium) or curcumin are implicated to have cancer protective effects (El-Bayoumy, Sinha, Cooper, \& Pinto, 2011; Shu et al., 2010). Frying and grilling of meat have been associated with formation of carcinogenic heterocyclic amines and polycyclic aromatic hydrocarbons that have been associated with a higher relative risk for CRC development in humans, (RR 1.18, Cross et al., 2010), but it must be noted that these compounds are also formed when grilling or frying chicken or fish and are therefore not specific to red meat (Moonen, Moonen, Maas, Kleinjans, \& de Kok, 2004).

Production and packaging of meat may also impact the risk for CRC. Anaerobic processing and packaging of ham are associated with reduced carcinogenesis in rats (Santarelli et al., 2010). Addition of certain phytochemicals to the meat may have both antimicrobial functions and cancer protective effects (de Oliveira et al., 2010; Shu et al., 2010). Beneficial changes may also be obtained by improved feeding of pigs and cattle (Gobert et al., 2010; Habeanu et al., 2014; Haug, Nyquist, Mosti, Andersen, \& Høstmark, 2012; Meineri, Medana, Giancotti, Visentin, \& Peiretti, 2013; Olmedilla-Alonso, JimenezColmenero, \& Sanchez-Muniz, 2013). The search for chemopreventive agents should continue, and their efficacy demonstrated in human volunteers. The best recipes and procedures can then be included in normal meat processing. The meat industry would then provide meat and meat products to consumers that minimize the risk for CRC development (Corpet, 2011).

\section{What should we do now?}

As it becomes clear from this paper, the interactions between meat, gut and health outcomes such as CRC are very complex and are not clearly pointing in one direction. There is a need for further studies on both the epidemiological relation between red meat and health and the underlying physiological mechanisms.

\subsection{Enhancing epidemiology studies with molecular markers}

Epidemiological studies are currently one of the few options available for studying the relation between red meat intake and CRC incidence in humans, but meat intake is usually measured by selfreporting, making it potentially inaccurate, particularly when done over a long period. The negative reputation of red meat may also lead to underreporting of intake among health-conscious individuals, thereby skewing the risk analysis in the direction of higher risk for red meat consumption. There is a lack of good objective markers of meat intake, as well as markers of how the meat was prepared, that can be used to accurately estimate intakes in relation to CRC development. It would be very useful for further epidemiological studies to have access to good biomarkers of intake for total protein, red meat, and white meat which work in clear contrast with markers of other protein-rich foods such as dairy products, fish or legumes. Moreover, biomarkers of processed and heated meat intake are needed. Preferably all these markers should also exist in versions that tell how long ago and in what quantity the meat was ingested. While this advanced biomarker identification has not been achieved yet, some metabolites emerge as potential markers. These may include total N2 and urea, 1- and 3-methyl-

\section{Box 3}

Whole food versus purified compound testing.

Studies that aim to test the effects of food on health can be done either using purified substances of the food, or using the whole food product which consists of complex mixtures of compounds. The different compounds in a food may have both beneficial and adverse effects, depending on the dose provided. In addition, the dose ranges will be limited in whole food testing to factors such as bulkiness of the foods, their palatability to the individual, and avoidance of nutritional imbalance. This also will have its bearing on the sensitivity of the model. The European Food Safety Authority (EFSA) has developed guidance for whole food testing of for example GM crops and irradiated foods in rodent models, including the design of such studies, statistical power, animal strain, housing and diet preparation among other things. While there may be a risk associated with high consumption of red and processed meat, there may also be protecting factors within the meat depending on its composition and preparation, and whole food testing may require more individuals and longer exposure times before effects on the CRC development can be shown. In contrast, use of purified compounds reflects a worst-casescenario that may be unrealistic but gives results faster with fewer individuals. In rodent models both whole food testing and experiments with purified compounds are conducted in order to investigate health effects and the underlying mechanisms. The EFSA guidelines for whole food testing are not expected to result in studies that identify red meat as a carcinogen as they require that the diet used for testing is nutritionally balanced. A major question, however, in relation to meat in the diet that remains is how the formation of carcinogenic compounds during the digestion of meat is modulated by nutrients and compounds from other food items in the meal. 
Box 4

Why should we keep eating red meat?

Strong media coverage and ambiguous research results could stimulate consumers to adapt a 'safety first' strategy that could result in abolishment of red meat from the diet completely. However, there are reasons to keep red meat in the diet. Red meat (beef in particular) is a nutrient dense food and typically has a better ratio of N6:N3-polyunsaturated fatty acids and significantly more vitamin A, B6 and B12, zinc and iron than white meat (compared values from the Dutch Food Composition Database 2013, raw meat). Iron deficiencies are still common in parts of the populations in both developing and industrialized countries, particularly pre-school children and women of childbearing age (WHO). It is clear however that iron intakes below the WHO recommended intakes $(20$ and $9 \mathrm{mg} / \mathrm{d}$ for women and men respectively) far exceed the incidence of anemia (Stoltzfus, 2001) and are not associated with clear functional disabilities (Millward \& Garnett, 2010). The equivalent availability of $\mathrm{Fe}$ from meat and from non-meat sources is now recognized associated with a tightly and complex homeostatic mechanism, controlled by hepcidin (Scientific Advisory Committee on Nutrition, 2010). Red meat also contains high levels of carnitine, coenzyme $\mathbf{Q} 10$, and creatine, which are bioactive compounds that may have positive effects on health (Schmid, 2009). The average consumer may not know how to correctly substitute for missing nutrients, which increases the risk for malnutrition in those consumers. In addition, many consumers would argue that the immediate enjoyment of red meat may outweigh a potential future health risk.

histidines, creatine and creatinine, carnitine and trimethylamine oxide (TMAO), and carnosine as overall markers of protein or meat intake, trans-fats as markers of ruminant products, and heterocyclic amines and advanced glycation endpoints (AGEs) as markers of heated foods (Dragsted, 2010; Poulsen et al., 2013), although generalization of the use of such markers across consumer segments need to be verified and validated. It is notable that the first attempt to use methylhistidines as markers of meat intake in a small cross-sectional study on adenoma recurrence reported no association between these markers and recurrence despite a significantly higher self-reporting of meat consumption in the patients who had recurrences (Cross et al., accepted for publication). Currently, use of stable isotopes ratios of ${ }^{13} \mathrm{C}$ and ${ }^{15} \mathrm{~N}$, particularly in human feces and urine, is being explored and validates as a marker of meat and fish intake (Kuhnle, Joosen, Kneale, \& O'Connell, 2013). In addition to the use of such markers of exposure, future molecular epidemiological studies should make advantage of the newest developments in genomics markers of early effects. Markers of cancer development at the level of gene expression changes and epigenetic mechanisms, as well as markers for gut inflammation, and changes in metabolomic profiles, will help to integrate epidemiological findings with underlying mechanisms and improve epidemiology. Markers of cancer development and gut inflammation, as well as advances in metabolomics, will help to integrate epidemiological findings with underlying mechanisms and potential bias.

\subsection{Improving food composition databases}

In addition to reliable measures of meat intake, it is also vital to have an up-to-date and accurate overview of the composition of different red meats. Most countries track the composition of their food, but often at frequencies defined by their accessibility to direct funding or indirect food industry funding; typically within $\sim 10$ years intervals. Few national authorities have the resources to keep up-to-date with all the developments and advances in the current food supply. Europe has its food compositional analysis in the EuroFIR database (http://www.eurofir. org), which contains national data from 26 countries (New Zealand and Canada being the only countries outside Europe). In order to determine how red meat or processed meat is related to health or disease risk, it is crucial to have access to updated data on the composition of the consumed meat. However, there may be a large variability between different pieces of red meat, due to breed/genetics, trimming, animal feed processing and choices, geographic feed origin, age at slaughtering and others, but also sampling procedures and analytical differences. For comparisons it is important to use a representative part of the carcass, such as the minced beef trimming standardized to $14-16 \%$ fat: this covers a large share of the edible part of the carcass (in Norway 40\%). It is also important to know whether the samples measured are representative for the entire country. Nutritional databases currently lack information about minimum and maximum values, or standard deviations of the measurements. Regarding the components measured, there is a lack of information on some nutrients in meat that may have health implications. Differentiation into inorganic iron and heme iron seems scarce (see http://nevo-online.rivm.nl/Default.aspx for an exception). Plant components (chlorophyll and polyphenols) or their metabolites are typically not included; neither are possible toxins produced for example during a suboptimal fermentation of harvested forage (see Versilovskis \& De Saeger, 2010, for an example of such a discussion). It is important that levels of present and emerging compounds suggestively linked to human diseases are all quantified and included in databases. This will make it more efficient to identify causal relationships.

\subsection{Explore improvements and alternatives within meat composition} and processing

Finally, there are windows of opportunity to improve meat composition and processing that need to be explored. When the most common nutrients are compared between countries, the fraction of polyunsaturated fatty acids, vitamins B1, B6, B9 (folate), B12, D and $\mathrm{E}$ and selenium show the largest variation (with the maximum average value being more than twice the minimum average value, http://www.eurofir.org). If the variability is large there is an opportunity for strategies that improve the composition, assuming the source of the variation is identified. The potential for such changes is seen in studies in which the meat composition was changed to benefit human health, for example by changing plant oils in the feed to obtain an $n 6 / n 3$ ratio in chicken meat to be $2: 1$ instead of 10:1 in conventional chicken meat (Haug et al., 2012). Meat product composition can also be improved by changes in meat processing. Epidemiological studies group all processed meats into one category, but there are many different methods of meat processing, using many different ingredients and ratios of macronutrients. This may obscure underlying relationship with one or more meat associated factors being associated with CRC risk while other factors are not. It is unlikely that all processed meats have the same effect on health (Alexander, Miller, Cushing, \& Lowe, 2010). There is a need to identify the health risks associated with different methods of processing and different recipes in order to ascertain where there is a need for improvement. Healthier alternatives need to be investigated once meat products that could benefit strongly from changes in processing methods have been identified. Replacing nitrite with phytochemicals, as currently is being explored in the PHYTOME project, is just one example of a possible improvement. Collaboration with the meat industry and public health authorities is vital for a successful implementation of research results into the food supply chain, in order to minimize the health risks of red meat consumption. 


\section{Conclusions}

Meat consumption may be associated with an increased risk of CRC in 'Western' food cultures. This may be due to a real cause-and-effect relationship but it should be kept in mind that associations may suffer from confounding effects. Meat contains a number of compounds of nutritional benefit and may not be carcinogenic as such but rather, when consumed in very high amounts, may result in an imbalanced diet and thereby increase the risk of developing CRC. These imbalances may likely result from lack of antagonistic agents, such as calcium or phytochemicals, to counteract cytotoxic and mutagenic products that result from interactions of heme with an unfavorable gut environment. Products formed in cured or heated meats may further enhance such damage. There is a need for further studies largely related to the underlying mechanisms as long as CRC remains a big burden of disease. Integrating epidemiology with relevant information such as biomarkers of meat intake, inflammation markers, gene expression changes or other predictors of cancer development, individual variation on genetic predisposition, stress and obesity parameters and gut microbiota would be a huge advantage. All tools available need to be used, including in vitro studies, in silico studies, in vivo animal studies and human intervention studies, depending on the specific hypotheses that are tested.

Heme iron and lipid oxidation products are established to have effects on CRC development in sensitive animal models fed with a semi-purified diet containing no vegetables or cereal fibers. Endogenous nitrite, particularly in combination with heme iron and fatty acids, is still linked to red meat and CRC based on weak associations from epidemiological studies. There is a need for further studies on the differences between red meat from mammals that is associated with CRC versus poultry meat that is not, differences between processed and fresh red meat and between different types of red meat products, as the health risks may not be the same. In addition, there may be other hypotheses related to red meat and CRC that have been studied little thus far, including a potential role for the gut-brain axis and the gut microbiome.

There are windows of opportunity for strategies that may reduce the risk of CRC. Modifying meat composition via animal feeding and breeding, improving meat processing by alternative methods such as adding phytochemicals and improving our diets and meals in general are strategies that need to be followed up. This may not just reduce the risk of CRC but may also be beneficial for reduction of obesity and cardiovascular diseases. In order to achieve this, researchers need to collaborate with the meat industry and public health authorities.

Another argument refers to the growing demand for food. Animals used for production of meat often eat soy and grain that could be used to feed directly. However, not all land is suitable for growing soy, grain or other corps, but may instead be suitable for grazing by cows, sheep and goats. As the human population is growing significantly and the demand for food is increasing (Parfitt, Barthel, \& Macnaughton, 2010), it is important to utilize the land available for the optimal purpose, which includes grazing on marginal lands and consequent consumption of red meat. In the future, our diet may be more determined by food availability than by how it affects health.

\section{Funding}

The workshop received financial support from a Research Levy on Agricultural Products/the Agricultural Agreement Research Fund grant 224794 and the Centre of Advanced Study 2013/2014 research group's award winning project: "The Ecology of Food Perception". Bjørg Egelandsdal, Marije Oostindjer and Gro V. Amdam are responsible for the "Ecology of Food Perception" research project. The funding sources had no other involvement in producing this paper.

\section{Conflict of interest}

NS Bryan and the University of Texas Health Science Center have financial interests in Neogenis Labs, Inc.

D Weed has received consulting fees from the National Cattleman's Beef Association in the past.

All other authors declare no conflict of interest.

\section{Acknowledgments}

A special thanks to Daniel Demeyer and Qing Wang for their comments on the manuscript, to Ellen Hovland for her great contribution to the arrangement and to Vladana Grabez for assisting in the organization of the event. The active input of all other participants is highly appreciated. The authors would also like to thank the two anonymous reviewers for their constructive comments and suggestions.

\section{References}

Akesson, B., \& Mercke, P. (Eds.). (2005). Biomarkers on dietary exposure to anticarcinogenic food components and their links to mechanisms of action. ECNIS Report. Lods, Poland: $\mathrm{NIOM}$

Alexander, J. (2000). Use of transgenic mice in identifying chemopreventive agents. Toxicology Letters, 15, 507-512.

Alexander, D.D. (2013). No association between meat intake and mortality in Asian countries. The American Journal of Clinical Nutrition, 98, 865-866.

Alexander, D.D., Miller, A. J., Cushing, C. A., \& Lowe, K. A. (2010). Processed meat and colorectal cancer: A quantitative review of prospective epidemiologic studies. European Journal of Cancer Prevention, 19, 328-341.

Alexander, D.D., Weed, D. L., Cushing, C. A., \& Lowe, K. A. (2011). Meta-analysis of prospective studies of red meat consumption and colorectal cancer. European Journal of Cancer Prevention, 20, 293-307.

Allam, O., Bahuaud, D., Tache, S., Naud, N., Corpet, D. E., \& Pierre, F. H. (2011). Calcium carbonate suppresses haem toxicity markers without calcium phosphate side effects on colon carcinogenesis. British Journal of Nutrition, 105, 384-392.

American Cancer Society (2011). Global cancer facts \& figures (2nd ed.). Atlanta: American Cancer Society.

Araújo, J., Gonçalves, P., \& Martel, F. (2011). Chemopreventive effect of dietary polyphenols in colorectal cancer cell lines. Nutrition Research, 32, 77-87.

Arslan, E., Atilgan, H., \& Yavaşoğlu, I. (2009). The prevalence of Helicobacter pylori in obese subjects. European Journal of Internal Medicine, 20, 695-697.

Arumugam, M., Raes, J., Pelletier, E., Le Paslier, D., Yamada, T., Mende, D. R., Fernandes, G. R., Tap, J., Bruls, T., Batto, J. M., Bertalan, M., Borruel, N., Casellas, F., Fernandez, L., Gautier, L., Hansen, T., Hattori, M., Hayashi, T., Kleerebezem, M., Kurokawa, K., Leclerc, M., Levenez, F., Manichanh, C., Nielsen, B., Nielsen, T., Pons, N., Poulain, J., Qin, J., Sicheritz-Ponten, T., Tims, S., Torrents, D., Ugarte, E., Zoetendal, E. G., Wang, J., Guarner, F., Pedersen, O., de Vos, W. M., Brunak, S., Doré, J., MetaHIT Consortium, Weissenbach, Ehrlich, S. D., \& Bork, P. (2011). Enterotypes of the human gut microbiome. Nature, 473, 174-180.

Atarashi, K., Tanoue, T., Oshima, K., Suda, W., Nagano, Y., Nishikawa, H., Fukuda, S., Saito, T. , Narushima, S., Hase, K., Kim, S., Fritz, J. V., Wilmes, P., Ueha, S., Matsushima, K., Ohno, H., Olle, B., Sakaguchi, S., Taniguchi, T., Morita, H., Hattori, M., \& Honda, K. (2013). Treg induction by a rationally selected mixture of Clostridia strains from the human microbiota. Nature, 500, 232-236.

Aune, D., Chan, D. S. M., Vieira, A.R., Navarro Rosenblatt, D. A., Vieira, R., Greenwood, D. C., Kampman, E., \& Norat, T. (2013). Red and processed meat intake and the risk of colorectal adenomas: A systematic review and meta-analysis of epidemiological studies. Cancer Causes and Control, 24, 611-627.

Azcárate-Peril, M.A., Sikes, M., \& Bruno-Bárcena, J. M. (2011). The intestinal microbiota, gastrointestinal environment and colorectal cancer: A putative role for probiotics in prevention of colorectal cancer? American Journal of Physiology - Gastrointestinal and Liver Physiology, 301, G401-G424.

Bartsch, H., \& Frank, N. (1996). Blocking the endogenous formation of N-nitroso compounds and related carcinogens. IARC Scientific Publication, 139, 189-201.

Bastide, N. M., Pierre, F. H. F., \& Corpet, D. E. (2011). Heme iron from meat and risk of colorectal cancer: A meta-analysis and a review of the mechanisms involved. Cancer Prevention Research, 4, 177-184.

Bellisari, A. (2008). Evolutionary origins of obesity. Obesity Reviews, 9, 165-180.

Brown, M.O., Lanier, A. P., \& Becker, T. M. (1998). Colorectal cancer incidence and survival among Alaska Natives, 1969-1993. International Journal of Epidemiology, 27, 388-396.

Bryan, N. S., Calvert, J. W., Elrod, J. W., Gundewar, S., Ji, S. Y., \& Lefer, D. J. (2007). Dietary nitrite supplementation protects against myocardial ischemia-reperfusion injury. Proceedings of the National Academy of Sciences, 104, 19144-19149.

Bryan, N. S., \& Loscalzo, J. (2011). Nitrite and nitrate in human health and disease. : Springer Humana Press (ISBN 978-1-60761-616-0).

Bugiardini, R., Manfrini, O., Pizzi, C., Fontana, F., \& Morgagni, G. (2004). Endothelial function predicts future development of coronary artery disease: A study of women with chest pain and normal coronary angiograms. Circulation, 109, 2518-2523. 
Byres, E., Paton, A. W., Paton, J. C., Lofling, J. C., Smith, D. F., Wilce, M. C., Talbot, U. M., Chong, D. C., Yu, H., Huang, S., Chen, X., Varki, N. M., Varki, A., Rossjohn, J., \& Beddoe, T. (2008). Incorporation of a non-human glycan mediates human susceptibility to a bacterial toxin. Nature, 456, 648-653.

Caderni, G., Femia, A. P., Giannini, A., Favuzza, A., Luceri, C., Salvadori, M., \& Dolara, P. (2003). Identification of mucin-depleted foci in the unsectioned colon of azoxymethane-treated rats: Correlation with carcinogenesis. Cancer Research, 63, 2388-2392.

Calle, E. E., \& Kaaks, R. (2004). Overweight, obesity and cancer: Epidemiological evidence and proposed mechanisms. Nature Reviews Cancer, 4, 579-591.

Carlström, M., Larsen, F. J., Nyström, T., Hezel, M., Borniquel, S., Weitzberg, E., \& Lundberg, J. O. (2010). Dietary inorganic nitrate reverses features of metabolic syndrome in endothelial nitric oxide synthase-deficient mice. Proceedings of the National Academy of Sciences, 107, 17716-17720.

Carlström, M., Persson, E. G., Larsson, E., Hezel, M., Scheffer, P. G., Teerlink, T., Weitzberg, E., \& Lundberg, J. O. (2011). Dietary nitrate attenuates oxidative stress, prevents cardiac and renal injuries, and reduces blood pressure in salt-induced hypertension. Cardiovascular Research, 89, 574-585.

Carothers, A.M., Melstrom, K. A., Jr., Mueller, J.D., Weyant, M. J., \& Bertagnolli, M. M. (2001). Progressive changes in adherens junction structure during intestinal adenoma formation in Apc mutant mice. Journal of Biological Chemistry, 276, 39094-39102.

Celermajer, D. S., Sorensen, K. E., Spiegelhalter, D. J., Georgakopoulos, D., Robinson, J., \& Deanfield, J. E. (1994). Aging is associated with endothelial dysfunction in healthy men years before the age-related decline in women. Journal of the American College of Cardiology, 24, 471-476.

Chan, D. S., Lau, R., Aune, D., Vieira, R., Greenwood, D. C., Kampman, E., \& Norat, T. (2011). Red and processed meat and colorectal cancer incidence: Meta-analysis of prospective studies. PLoS One, 6, e20456.

Chung, M. Y., Lim, T. G., \& Lee, K. W. (2013). Molecular mechanisms of chemopreventive phytochemicals against gastroenterological cancer development. World Journal of Gastroenterology, 19, 984-993.

Corpet, D. E. (2011). Red meat and colon cancer: Should we become vegetarians, or can we make meat safer? Meat Science, 89, 310-316.

Corpet, D. E., \& Pierre, F. (2005). How good are rodent models of carcinogenesis in predicting efficacy in humans? A systematic review and meta-analysis of colon chemoprevention in rats, mice and men. Eur Journal of Cancer, 41, 1911-1922.

Cross, A. J., Ferrucci, L. M., Risch, A., Graubard, B. I., Ward, M. H., Park, Y., Hollenbeck, A.R., Schatzkin, A., \& Sinha, R. (2010). A large prospective study of meat consumption and colorectal cancer risk: An investigation of potential mechanisms underlying this association. Cancer Research, 70, 2406-2414.

Cross, A., Major, J. M., Rothman, N., \& Sinha, R. (2014). Urinary 1- and 3-methylhistidine, meat intake, and colorectal adenoma risk. European Journal of Cancer Prevention (accepted for publication).

Cross, A. J., Pollock, J. R., \& Bingham, S. A. (2003). Haem, not protein or inorganic iron, is responsible for endogenous intestinal $\mathrm{N}$-nitrosation arising from red meat. Cancer Research, 63, 2358-2360.

Cryan, J. F., \& Dinan, T. G. (2012). Mind-altering microorganisms: The impact of the gut microbiota on brain and behaviour. Nature reviews neuroscience, 13, 701-712.

Davignon, J., \& Ganz, P. (2004). Role of endothelial dysfunction in atherosclerosis. Circulation, 109, III-27-III-32.

De Kok, T. M., van Breda, S. G., \& Briedé, J. J. (2012). Genomics-based identification of molecular mechanisms behind the cancer preventive action of phytochemicals: Potentials and challenges. Current Pharmaceutical Biotechnology, 13, 255-264.

de Kok, T. M., van Breda, S. G., \& Manson, M. M. (2008). Mechanisms of combined action of different chemopreventive dietary compounds: A review. European Journal of Nutrition, 47(Suppl. 2), 51-59.

de Oliveira, C. E. V., Stamford, T. L. M., Neto, N. J. G., \& de Souza, E. L. (2010). Inhibition of Staphylococcus aureus in broth and meat broth using synergies of phenolics and organic acids. International Journal of Food Microbiology, 137, 312-316.

Derrien, M., van Passel, M. W. J., van de Bovenkamp, J. H. B., Schipper, R., de Vos, W., \& Dekker, J. (2010). Mucin-bacterial interactions in the human oral cavity and digestive tract. Gut Microbes, 1, 254-268.

Dethlefsen, L., McFall-Ngai, M., \& Relmen, D. A. (2007). An ecological and evolutionary perspective on human-microbe mutualism and disease. Nature, 449, 811-818.

Dommels, Y. E. M., Haring, M. M. G., Keestra, N. G. M., Alink, G. M., van Bladeren, P. J., \& van Ommen, B. (2003). The role of cyclooxygenase in $n-6$ and $n-3$ polyunsaturated fatty acid mediated effects on cell proliferation, PGE2 synthesis and cytotoxicity in human colorectal carcinoma cell lines. Carcinogenesis, 24, 385-392.

Dragsted, L. O. (2010). Biomarkers of meat intake and the application of nutrigenomics. Meat Science, 84, 301-307.

E.U. Fact Sheet (2004). The meat sector in the European Union. Available at. http://ec. europa.eu/agriculture/publi/fact/meat/2004_en.pdf

EFSA (2011). Guidance on conducting repeated-dose 90-day oral toxicity study in rodents on whole food/feed. EFSA Journal, 9, 2438, http://dx.doi.org/10.2903/j. efsa.2011.2438.

Egashira, K., Inou, T., Hirooka, Y., Kai, H., Sugimachi, M., Suzuki, S., Kuga, T., Urabe, Y., \& Takeshita, A. (1993). Effects of age on endothelium-dependent vasodilation of resistance coronary artery by acetylcholine in humans. Circulation, 88, 77-81.

Eigler, A., Sinha, B., Hartmann, G., \& Endres, S. (1997). Taming TNF: strategies to restrain this proinflammatory cytokine. Immunology Today, 18, 487-492.

Elamin, E., Jonkers, D., Juuti-Uusitalo, K., van IJzendoorn, S., Troost, F., Duimel, H., Broers, J., Verheyen, F., Dekker, J., \& Masclee, A. (2012). Effects of ethanol and acetaldehyde on tight junction integrity: In vitro study in a three dimensional intestinal epithelial cell culture model. PLoS One, 7, e35008.

El-Bayoumy, K., Sinha, R., Cooper, A. J. L., \& Pinto, J. T. (2011). The role of alliums and their sulphur and selenium constituents in cancer prevention. Diet and Cancer, 2, 91-121.
EU Directive 2006/52/EC (). Available at. http://eur-lex.europa.eu/LexUriServ/LexUriServ. do? uri=OJ:L:2006:204:0010:0022:EN:PDF

Fantini, M. C., \& Pallone, F. (2008). Cytokines: from gut inflammation to colorectal cancer Current Drug Targets, 9, 375-380.

FAOSTAT for protein intake (2012). Available at. http://faostat.fao.org/site/610/default aspx\#ancor

Fearnhead, N. S., Britton, M. P., \& Bodmer, W. F. (2001). The Abc of Apc. Human Molecular Genetics, 10, 721-733.

Femia, A. P., Dolara, P., Luceri, C., Salvadori, M., \& Caderni, G. (2009). Mucin-depleted foci show strong activation of inflammatory markers in 1,2-dimethylhydrazine-induced carcinogenesis and are promoted by the inflammatory agent sodium dextran sulfate. International Journal of Cancer, 125, 541-547.

Femia, A. P., Paulsen, J. E., Dolara, P., Alexander, J., \& Caderni, G. (2008). Correspondence between flat aberrant crypt foci and mucin-depleted foci in rodent colon carcinogenesis. Anticancer Research, 28, 3771-3775.

Ferlay, J., Steliarova-Foucher, E., Lortet-Tieulent, J., Rosso, S., Coebergh, J. W., Comber, H. Forman, D., \& Bray, F. (2013). Cancer incidence and mortality patterns in Europe: Estimates for 40 countries in 2012. European Journal of Cancer, 49, 1374-1403.

Field, B. C. T., Chaudri, O. B., \& Bloom, S. R. (2010). Bowels control brain: Gut hormones and obesity. Nature Reviews Endocrinology, 6, 444-453.

Fodde, R. (2002). The APC gene in colorectal cancer. European Journal of Cancer, 38, 867-871

Fodde, R., \& Smits, R. (2001). Disease model: Familial adenomatous polyposis. Trends in Molecular Medicine, 7, 369-373.

Fraser, G. E. (1999). Associations between diet and cancer, ischemic heart disease, and allcause mortality in non-Hispanic white California Seventh-day Adventists. American Journal of Clinical Nutrition, 70, 532S-538S.

Gerhard, M., Roddy, M.A., Creager, S. J., \& Creager, M.A. (1996). Aging progressively impairs endothelium-dependent vasodilation in forearm resistance vessels of humans. Hypertension, 27, 849-853.

Glei, M., Latunde-Dada, G. O., Klinder, A., Becker, T. W., Hermann, U., Voigt, K., \& Pool-Zobel, B.L. (2002). Iron-overload induces oxidative DNA damage in the human colon carcinoma cell line HT29 clone 19A. Mutation Research/Genetic Toxicology and Environmental Mutagenesis, 519, 151-161.

Gobert, M., Gruffat, D., Habeanu, M., Parafita, E., Bauchart, D., \& Durand, D. (2010). Plant extracts combined with vitamin E in PUFA-rich diets of cull cows protect processed beef against lipid oxidation. Meat Science, 85, 676-683.

Goessling, W., North, T. E., Lord, A.M., Ceol, C., Lee, S., Weidinger, G., Bourque, C., Strijbosch, R., Haramis, A. P., Puder, M., Clevers, H., Moon, R. T., \& Zon, L. I. (2008) APC mutant zebrafish uncover a changing temporal requirement for wnt signalling in liver development. Developmental Biology, 320, 161-174.

Habeanu, M., Thomas, A., Bispo, E., Gobert, M., Gruffat, D., Durand, D., \& Bauchart, D. (2014). Extruded linseed and rapeseed both influenced fatty acid composition of total lipids and their polar and neutral fractions in longissimus thoracis and semitendinosus muscles of finishing Normand cows. Meat Science, 96, 99-107.

Hague, A., Butt, A. J., \& Paraskeva, C. (1996). The role of butyrate in human colonic epithelial cells: An energy source or inducer of differentiation and apoptosis? Proceedings of the Nutrition Society, 55, 937-943.

Halcox, J. P. J., Schencke, W. H., Zalos, G., Mincemoyer, R., Prasad, A., Waclawiw, M.A. Nour, K. R. A., \& Quyyumi, A. A. (2002). Progronstic value of coronary vascular endothelial dysfunction. Circulation, 106, 653-658.

Half, E., Bercovich, D., \& Rozen, P. (2009). Familial adenomatous polyposis. Orphanet Journal of Rare Diseases, 4, 22.

Hassler, S., Sjölander, P., Grönberg, H., Johansson, R., \& Damber, L. (2008). Cancer in the Sami population of Sweden in relation to lifestyle and genetic factors. European Journal of Epidemiology, 23, 273-280.

Haug, A., Nyquist, N. F., Mosti, T. J., Andersen, M., \& Høstmark, A. T. (2012). Increased EPA levels in serum phospholipids of humans after four weeks daily ingestion of one portion chicken fed linseed and rapeseed oil. Lipids in Health and Disease, 11, 104-115.

Hebels, D.G., Jennen, D.G., van Herwijnen, M. H., Georgiadis, P. A., Moonen, E. J., Pedersen, M., Knudsen, L. E., Kleinjans, J. C., \& Kok, T. M. (2011). Whole-genome gene expression modifications associated with nitrosamine exposure and micronucleus frequency in human blood cells. Mutagenesis, 26, 753-761.

Hebels, D.G., Sveje, K. M., de Kok, M. C., van Herwijnen, M. H., Kuhnle, G. C., Engels, L. G. Vleugels, C. B., Mares, W. G., Pierik, M., Masclee, A. A., Kleinjans, J. C., \& de Kok, T. M. (2011). N-Nitroso compound exposure-associated transcriptomic profiles are indicative of an increased risk for colorectal cancer. Cancer Letters, 309, 1-10.

Hebels, D.G., Sveje, K. M., de Kok, M. C., van Herwijnen, M. H., Kuhnle, G. G., Engels, L. G. Vleugels-Simon, C. B., Mares, W. G., Pierik, M., Masclee, A. A., Kleinjans, J. C., \& de Kok, T. M. (2012). Red meat intake-induced increases in fecal water genotoxicity correlate with pro-carcinogenic gene expression changes in the human colon. Food and Chemical Toxicology, 50, 95-103.

Hedlund, M., Padler-Karavani, V., Varki, N. M., \& Varki, A. (2008). Evidence for a humanspecific mechanism for diet and antibody-mediated inflammation in carcinoma progression. Proceedings of the National Academy of Sciences of the United States of America, 105, 18936-18941.

Hildebrandt, M.A., Hoffman, C., Sherrill-Mix, S. A., Keilbaugh, S. A., Hamady, M., Chen, Y. Knight, R., Ahima, R. S., Bushman, F., \& Wu, G. D. (2009). High fat diet determines the composition of the murine gut microbiome independently of obesity. Gastroenterology, 137, 1716-1724.

Hill, J. O., Wyatt, H. R., Reed, G. W., \& Peters, J. C. (2003). Obesity and the environment Where do we go from here? Science, 299, 853-855.

Holt, S. H., Miller, J. C., Petocz, P., \& Farmakalidis, E. (1995). A satiety index of common foods. European Journal of Clinical Nutrition, 49, 675-690.

Hord, N. G., Tang, Y., \& Bryan, N. S. (2009). Food sources of nitrates and nitrites: The physiologic context for potential health benefits. American Journal of Clinical Nutrition, 90, 1-10. 
Hughes, S. A., Carothers, A.M., Hunt, D. H., Moran, A. E., Mueller, J.D., \& Bertagnolli, M. M. (2002). Adenomatous polyposis coli truncation alters cytoskeletal structure and microtubule stability in early intestinal tumorigenesis. Journal of Gastrointestinal Surgery, 6, 868-874.

IARC (2010). Ingested nitrate and nitrite, and cyanobacterial peptide toxins. IARC monographs on the evaluation of carcinogenic risks to humans, 94, (Available at http://monographs.iarc.fr/ENG/Monographs/vol94/mono94.pdf).

IJssennagger, N., Rijnierse, A., de Wit, N. J. W., Boekschoten, M. V., Dekker, J., Schonewille, A., Müller, M., \& van der Meer, R. (2013). Dietary heme induces acute oxidative stress, but delayed cytotoxicity and compensatory hyperproliferation in mouse colon. Carcinogenesis, 34, 1628-1635.

Ishikawa, S., Tamaki, S., Ohata, M., Arihara, K., \& Itoh, M. (2010). Heme induces DNA damage and hyperproliferation of colonic epithelial cells via hydrogen peroxide produced by heme oxygenase: A possible mechanism of heme-induced colon cancer. Molecular Nutrition E Food Research, 54, 1182-1191.

Jaiswal, M., LaRusso, N. F., Burgart, L. J., \& Gores, G. J. (2000). Inflammatory cytokines induce DNA damage and inhibit DNA repair in chalngiocarcinoma cells by a nitric oxide-dependent mechanism. Cancer Research, 60, 184-190.

Jia, X., Naito, H., Yetti, H., Tamada, H., Kitamori, K., Hayashi, Y., Wang, D., Yanagiba, Y., Wang, J., Ikeda, K., Yamori, Y., \& Nakajima, T. (2013). Dysregulated bile acid synthesis metabolism and excretion in a high fat-cholesterol diet-induced fibrotic steatohepatitis in rats. Digestive Diseases and Sciences, 58, 2212-2222.

Joosen, A.M., Kuhnle, G. G., Aspinall, S. M., Barrow, T. M., Lecommandeur, E., Azqueta, A., Collins, A.R., \& Bingham, S. A. (2009). Effect of processed and red meat on endogenous nitrosation and DNA damage. Carcinogenesis, 30, 1402-1407.

Kakizoe, T., Wang, T. T., Eng, V. W. S., Furrer, R., Dion, P., \& Bruce, W. R. (1979). Volatile $\mathrm{N}$-Nitrosamines in the urine of normal donors and of bladder cancer patients. Cancer Research, 39, 829.

Keenan, M. J., Martin, R. J., Raggio, A.M., McCutcheon, K. L., Brown, I. L., Birkitt, A. Newman, S. S., Skaf, J., Hegsted, M., Tulley, R. T., Blair, E., \& Zhou, J. (2012) A microarray study indicates high-amylose resistant starch increases hormones and improves structure and function of the GI tract. Journal of Nutrigenetics and Nutrigenomics, 5, 26-44.

Kelloff, G. J., Schilsky, R. L., Alberts, D. S., Day, R. W., Guyton, K. Z., Pearce, H. L., Peck, J. C., Phillips, R., \& Sigman, C. C. (2004). Colorectal adenomas: A prototype for the use of surrogate end points in the development of cancer prevention drugs. Clinical Cancer Research, 10, 3908-3918.

Key, T. J., Appleby, P. H., Spencer, E. A., Travis, R. C., Roddam, A. W., \& Allen, N. E. (2009) Cancer incidence in vegetarians: Results from the European Prospective Investigation in Cancer and Nutrition (EPIC-Oxford). American Journal of Clinical Nutrition, 89, 1620S-1626S

Kinzler, K. W., \& Vogelstein, B. (1996). Lessons from hereditary colon cancer. Cell, 87, $159-170$.

Kinzler, K. W., \& Vogelstein, B. (1997). Cancer-susceptibility genes - Gatekeepers and caretakers. Nature, 386, 761.

Kleinbongard, P., Dejam, A., Lauer, T., Jax, T., Kerber, S., Gharini, P., Balzer, J., Zotz, R. B. Scharf, R. E., Willers, R., Schechter, A. N., Feelisch, M., \& Kelm, M. (2006). Plasma nitrite concentrations reflect the degree of endothelial dysfunction in humans. Free Radical Biology and Medicine, 40, 295-302.

Kodama, Y., Zhao, C. M., Quante, M., Mutapalani, S, Flatberg A, Friedman, R. A, Sandvik, A. K., Fox, J. G., Kaneko, K., Wang, T. C., \& Chen, D. (2012). Vagotomy suppresses gastric cancer progression in mice. Gastroenterology, 142, S-327.

Kroboth, K., Newton, I. P., Kita, K., Dikovskaya, D., Zumbrunn, J., Waterman-Storer, C. M., \& Näthke, I. S. (2007). Lack of adenomatous polyposis coli protein correlates with decrease in cell migration and overall changes in microtubule stability. Molecular Biology of the Cell, 18, 910-918.

Kuhnle, G. G. C., Joosen, A.M. C. P., Kneale, C. J., \& O'Connell, T. C. (2013). Carbon and nitrogen isotopic ratios of urine and faeces as novel nutritional biomarkers of meat and fish intake. European Journal of Nutrition, 52, 389-395.

Kuhnle, G. G., Story, G. W., Reda, T., Mani, A.R., Moore, K. P., Lunn, J. C., \& Bingham, S. A (2007). Diet-induced endogenous formation of nitroso compounds in the GI tract. Free Radical Biology \&' Medicine, 43, 1040-1047.

Lai, C. Y., Baumann, L., \& Baumann, P. (1994). Amplification of trpEG: Adaptation of Buchnera aphidicola to an endosymbiotic association with aphids. Proceedings of the National Academy of Sciences of the United States of America, 91, 3819-3823.

Larsson, S.C., Kumlin, M., Ingelman-Sundberg, M., \& Wolk, A. (2004). Dietary long-chain $\mathrm{n}-3$ fatty acids for the prevention of cancer: A review of potential mechanisms. American Journal of Clinical Nutrition, 79, 935-945.

Larsson, S.C., \& Wolk, A. (2006). Meat consumption and risk of colorectal cancer: A meta-analysis of prospective studies. International Journal of Cancer, 119 2657-2664.

Latunde-Dada, G. O., Simpson, R. J., \& McKie, A. T. (2006). Recent advances in mammalian haem transport. Trends in Biochemical Sciences, 31, 182-188

Lee, R. A., Kim, H. A., Kang, B. Y., \& Kim, K. H. (2006). Hemoglobin induces colon cancer cell proliferation by release of reactive oxygen species. World Journal of Gastroenterology, $12,5644-5650$

Lerman, A., \& Zeiher, A.M. (2005). Endothelial function: Cardiac events. Circulation, 111 363-368.

Leslie, A., Carey, F. A., Pratt, N. R., \& Steele, R. J. C. (2002). The colorectal adenomacarcinoma sequence. British Journal of Surgery, 89, 845-860

Lombardi-Boccia, G., Martinez-Dominguez, B., \& Aguzzi, A. (2002). Total heme and non-heme iron in raw and cooked meats. Journal of Food Science, 67, $1738-1741$.

Lundberg, J. O., Weitzberg, E., \& Gladwin, M. T. (2008). The nitrate-nitrite-nitric oxide pathway in physiology and therapeutics. Nature Reviews Drug Discovery, 7, 156-167.
Magrone, T., \& Jirillo, E. (2013). The interplay between the gut immune system and microbiota in health and disease: Nutraceutical intervention for restoring intestinal homeostasis. Current Pharmaceutical Design, 19, 1329-1342.

McAfee, A. J., McSorley, E. M., Cuskelly, G. J., Moss, B. W., Wallace, J. M. W., Bonham, M. P., \& Fearon, A.M. (2010). Red meat consumption: An overview of the risks and benefits. Meat Science, 84, 1-13.

McCanna, M. J., Gilla, C. I. R., O' Briena, G., Raob, J. R., McRoberts, W. C., Hughes, P., McEntee, R., \& Rowland, I. R. (2007). Anti-cancer properties of phenolics from apple waste on colon carcinogenesis in vitro. Food and Chemical Toxicology, 45, 1224-1230.

Meineri, G., Medana, C., Giancotti, V., Visentin, S., \& Peiretti, P. G. (2013). Effect of dietary supplementation of vitamin $\mathrm{E}$ in pigs to prevent the formation of carcinogenic substances in meat products. Journal of Food Composition and Analysis, 30, 67-72

Migliore, L., Migheli, F., Spisni, R., \& Coppede, F. (2011). Genetics, cytogenetics, and epigenetics of colorectal cancer. Journal of Biomedicine and Biotechnology (Article ID 792362).

Milkowski, A. L. (2011). Sources of exposure to nitrogen oxides. In N. S. Bryan, \& J. Loscalzo (Eds.), Nitrite and Nitrate in Human Health and Disease (pp. 49-65). New York: Humana Press.

Millward, D. J., \& Garnett, T. (2010). Food and the planet: Nutritional dilemmas of greenhouse gas emission reductions through reduced intakes of meat and dairy foods. Proceedings of the Nutrition Society, 69, 103-118.

Moellering, D. R., \& Smith, D. L., Jr. (2012). Ambient temperature and obesity. Current Obesity Reports, 1, 26-34.

Moonen, J. J., Moonen, E. J. C., Maas, L., Kleinjans, J. C. S., \& de Kok, T. M. (2004). NAT-2 and CYP1A2 activities and urinary excretion of 2-amino-1-methyl-6-phenylimidazo[4,5b]pyridine (PhIP) in a human dietary intervention study. Food Chemistry and Toxicology, 42, 869-878.

Moore, L. L., Bradlee, M. L., Singer, M. R., Splansky, G. L., Proctor, M. H., Ellison, R. C., \& Kreger, B. E. (2004). BMI and waist circumference as predictors of lifetime colon cancer risk in Framingham Study adults. International Journal of Obesity, 559-567.

Musso, G., Gambino, R., \& Cassader, M. (2010). Obesity, diabetes and gut microbiota, the hygiene hypothesis expanded? Diabetes Care, 33, 2277-2284.

Mutanen, M., Pajari, A.M., \& Oikarinen, S. I. (2000). Beef induces and rye bran prevents the formation of intestinal polyps in apc(min) mice: Relation to beta-catenin and PKC isozymes. Carcinogenesis, 21, 1167-1173.

Nasser, M. I., Bibi, F., Alqahtani, M. H., Chaudhary, A. G., Azhar, E. I., Kamal, M. A. \& Yasir, M. (2013). Role of gut microbiota in obesity, type 2 diabetes and Alzheimer's. CNS \&' Neurological Disorders - Drug Targets (Epub ahead of print).

NNR (2012). Nordic nutrition recommendations: Summary. http://www.norden.org/no/ publikationer/publikasjoner/nord-2013-009

Norat, T., Lukanova, A., Ferrari, P., \& Riboli, E. (2002). Meat consumption and colorectal cancer risk: Dose-response meta-analysis of epidemiological studies. International Journal of Cancer, 98, 241-256.

NTP (2001). NTP technical report on the toxicology and carcinogenesis studies of sodium

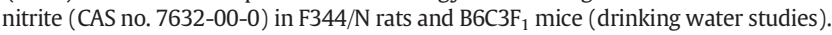
(Available at http://ntp.niehs.nih.gov/ntp/htdocs/LT_rpts/tr495.pdf)

Nunez De Gonzalez, M. T., Osburn, W. N., Hardin, M.D., Longnecker, M., Garg, H. K., Bryan, N. S., \& Keeton, J. T. (2012). Survey of residual nitrite and nitrate in conventional and organic/natural/uncured/indirectly cured meats available at retail in the United States. Journal of Agricultural and Food Chemistry, 60, 3981-3990.

Ohtake, K., Koga, M., Uchida, H., Sonoda, K., Ito, J., Uchida, M., Natsume, H., \& Kobayashi, J. (2010). Oral nitrite ameliorates dextran sulfate sodium-induced acute experimental colitis in mice. Nitric Oxide, 23, 65-73.

Ollberding, N. J., Nomura, A.M., Wilkens, L. R., Henderson, B. E., \& Kolonel, L. N. (2011). Racial/ethnic differences in colorectal cancer risk: The multiethnic cohort study. International Journal of Cancer, 129, 1899-1906.

Olmedilla-Alonso, B., Jimenez-Colmenero, F., \& Sanchez-Muniz, F. J. (2013). Development and assessment of healthy properties of meat and meat products designed as functional foods. Meat Science, 95, 919-930.

Ølstørn, H. B.A. (2009). The effect of acrylamide and glycidamide on intestinal carcinogenesis in mice. PhD dissertation. University of Oslo: Faculty of Mathematics and Natural Sciences.

Parfitt, J., Barthel, M., \& Macnaughton, S. (2010). Food waste within food supply chains: Quantification and potential for change to 2050. Philosophical Transactions of the Royal Society B, 365, 3065-3081.

Parnaud, G., \& Corpet, D. E. (1997). Colorectal cancer: Controversial role of meat consumption. Bulletin du Cancer, 84, 899-911.

Parnaud, G., Peiffer, G., Tache, S., \& Corpet, D. E. (1998). Effect of meat (beef, chicken, and bacon) on rat colon carcinogenesis. Nutrition and Cancer, 32, 165-173.

Parr, C. L., Hjartaker, A., Lund, E., \& Veierod, M. B. (2013). Meat intake, cooking methods and risk of proximal colon, distal colon and rectal cancer: The Norwegian Women and Cancer (NOWAC) cohort study. International Journal of Cancer, 133, 1153-1163.

Paulsen, J. E. (2000). Modulation by dietary factors in murine FAP models. Toxicology Letters, 112-113, 403-409.

Paulsen, J. E., Namork, E., Steffensen, I. L., Eide, T. J., \& Alexander, J. (2000). Identification and quantification of aberrant crypt foci in the colon of min mice - A murine model of familial adenomatous polyposis. Scandinavian Journal of Gastroenterology, $35,534-539$

Paulsen, J. E., Steffensen, I. L., Loberg, E. M., Husoy, T., Namork, E., \& Alexander, J. (2001). Qualitative and quantitative relationship between dysplastic aberrant crypt foci and tumorigenesis in the Min/+ mouse colon. Cancer Research, 61, 5010-5015.

Pegg, R. B., \& Shahidi, F. (2000). Nitrite curing of meat: The N-nitrosamine problem and nitrite alternatives. Chapter 2: Nitrite curing of meat. Trumbull: Wiley-Blackwell (ISBN 0-917678-50-9).

Pegg, R. B., \& Shahidi, F. (2000). Nitrite curing of meat: The N-nitrosamine problem and nitrite alternatives. Chapter 1: Introduction. Trumbull: Wiley-Blackwell (ISBN 0-917678-50-9). 
Pegg, R. B., \& Shahidi, F. (2000). Nitrite curing of meat: the N-nitrosamine problem and nitrite alternatives. Chapter 8: Potential health concerns about nitrate. Trumbull: Wiley-Blackwell (ISBN 0-917678-50-9).

Perše, M. (2013). Oxidative stress in the pathogenesis of colorectal cancer: Cause or consequence? BioMed Research International, http://dx.doi.org/10.1155/2013/ 725710 (Article ID 725710).

Pierre, F., Freeman, A., Tache, S., Van der Meer, R., \& Corpet, D. E. (2004). Beef meat and blood sausage promote the formation of azoxymethane-induced mucin-depleted foci and aberrant crypt foci in rat colons. Journal of Nutrition, 134, 2711-2716.

Pierre, F. H., Martin, O. C., Santarelli, R. L., Tache, S., Naud, N., Gueraud, F., Audebert, M., Dupuy, J., Meunier, N., Attaix, D., Vendeuvre, J. L., Mirvish, S. S., Kuhnle, G. C., Cano, N., \& Corpet, D. E. (2013). Calcium and alpha-tocopherol suppress cured-meat promotion of chemically induced colon carcinogenesis in rats and reduce associated biomarkers in human volunteers. American Journal of Clinical Nutrition, 98, $1255-1262$.

Pierre, F., Santarelli, R., Tache, S., Gueraud, F., \& Corpet, D. E. (2008). Beef meat promotion of dimethylhydrazine-induced colorectal carcinogenesis biomarkers is suppressed by dietary calcium. British Journal of Nutrition, 99, 1000-1006.

Pierre, F., Tache, S., Petit, C. R., Van der Meer, R., \& Corpet, D. E. (2003). Meat and cancer: Haemoglobin and haemin in a low-calcium diet promote colorectal carcinogenesis at the aberrant crypt stage in rats. Carcinogenesis, 24, 1683-1690.

Poulsen, M. W., Hedegaard, R. V., Andersen, J. M., de Courten, B., Bügel, S., Nielsen, J. Skibsted, L. H., \& Dragsted, L. O. (2013). Advanced glycation end products in food and their effects on health. Food Chemistry and Toxicology, 60, 10-37.

Preston, S. L., Leedham, S. J., Oukrif, D., Deheregoda, M., Goodlad, R. A., Poulsom, R., Alison, M. R., Wright, N. A., \& Novelli, M. (2008). The development of duodenal microadenomas in FAP patients: The human correlate of the Min mouse. Journal of Pathology, 214, 294-301.

Programme National Nutrition Santé (2009). Nutrition E Prévention des cancers: Des connaissances scientifiques aux recommendations. (France, Available from: URL: <http://www.hnpcc-lynch.com/INCa_brochure_pnns_nutrition160209. pdf $>$ ).

Rassaf, T., Lauer, T., Heiss, C., Balzer, J., Mangold, S., Leyendecker, T., Rottler, J., Drexhage, C., Meyer, C., \& Kelm, M. (2007). Nitric oxide synthase-derived plasma nitrite predicts exercise capacity. British Journal of Sports Medicine, 41, 669-673.

Riediger, N. D., Othman, R. A., Suh, M., \& Moghadasian, M. (2009). Systematic review of the roles of $\mathrm{n}-3$ fatty acids in health and disease. Journal of the American Dietetic Association, 109, 668-679.

Rodriguez-Ramiro, I., Martin, M.A., Ramos, S., Bravo, L., \& Goya, L. (2011). Comparative effects of dietary flavanols on antioxidant defences and their response to oxidantinduced stress on $\mathrm{CaCO}_{2}$ cells. European Journal of Nutrition, 50, 313-322.

Rokkas, T., Sechopoulos, P., Pistiolas, D., Kothonas, F., Margantinis, G., \& Koukoulis, G. (2013). The relationship of Helicobacter pylori infection and colon neoplasia, on the basis of meta-analysis. European Journal of Gastroenterology \& Hepatology, $25,1286-1294$.

Rudi, K., Storrø, O., Øien, T., \& Johnsen, R. (2012). Modelling bacterial transmission in human allergen-specific IgE sensitization. Letters in Applied Microbiology, 54 447-454.

Sanjoaquin, M.A., Appleby, P. N., Thorogood, M., Mann, J. I., \& Key, T. J. (2004). Nutrition, lifestyle and colorectal cancer incidence: a prospective investigation of 10998 vegetarians and non-vegetarians in the United Kingdom. British Journal of Cancer, 90, 118-121.

Santarelli, R. L., Naud, N., Tache, S., Gueraud, F., Vendeuvre, J. L., Zhou, L., Anwar, M. M., Mirvish, S. S., Corpet, D. E., \& Pierre, F. H. (2013). Calcium inhibits promotion by hot dog of 1,2-dimethylhydrazine-induced mucin-depleted foci in rat colon. International Journal of Cancer, 133, 2533-2541.

Santarelli, R. L., Vendeuvre, J. L., Naud, N., Tache, S., Gueraud, F., Viau, M., Genot, C., Corpet, D. E., \& Pierre, F. H. (2010). Meat processing and colon carcinogenesis: cooked, nitrite-treated, and oxidized high-heme cured meat promotes mucin-depleted foci in rats. Cancer Prevention Research (Philadelphia), 3, 852-864.

Schächinger, V., Britten, M. B., \& Zeihe, A.M. (2000). Prognostic impact of coronary vasodilator dysfunction on adverse long-term outcome of coronary heart disease. Circulation, 1899-1906.

Scharlau, D., Borowicki, A., Habermann, N., Hofmann, T., Klenow, S., Miene, C., Munjal, U., Stein, K., \& Glei, M. (2009). Mechanisms of primary cancer prevention by butyrate and other products formed during gut flora-mediated fermentation of dietary fibre. Mutation Research/Reviews in Mutation Research, 682, 39-53.

Schmid, A. (2009). Bioactive substances in meat and meat products. Fleisch Wirtschaft, 89 83-90.

Schonfeldt, H. C., \& Hall, N. G. (2012). Consumer education on the health benefits of red meat - A multidisciplinary approach. Food Research International, 47, $152-155$.

Scientific Advisory Committee on Nutrition (2010). Iron and Health Report UK (Available from: URL: <http://www.sacn.gov.uk/pdfs/sacn_iron_and health_report_web.pdfs).

Serban, D. E. (2013). Gastrointestinal cancers: Influence of gut microbiota, probiotics and prebiotics. Cancer Letters (pii: S0304-3835(13)00588-0).

Shin, S. Y., Yoon, H., Seunghyun, A., Kim, D. W., Kim, S. H., Koh, D., Lee, Y. H., \& Lim, Y. (2013). Chromenylchalcones showing cytotoxicity on human colon cancer cell lines and in silico docking with aurora kinases. Bioorganic $\mathcal{E}$ Medicinal Chemistry, 21, 4250-4258.

Shu, L., Cheung, K. L., Khor, T. O., Chen, C., \& Kong, A. N. (2010). Phytochemicals: Cancer chemoprevention and suppression of tumor onset and metastasis. Cancer and Metastasis Reviews, 29, 483-502.
Sindelar, J. J., \& Milkowski, A. L. (2012). Human safety controversies surrounding nitrate and nitrite in the diet. Nitric Oxide, 26, 259-266.

Speakman, J. R. (2007). A nonadaptive scenario explaining the genetic predisposition to obesity: The "Predation Release" hypothesis. Cell Metabolism, 6, 5-12.

Speakman, J. R. (2008). Thrifty genes for obesity, an attractive but flawed idea, and an alternative perspective: The 'drifty gene' hypothesis. International Journal of Obesity, 32, 1611-1617.

Steffensen, I. L., Paulsen, J. E., Eide, T. J., \& Alexander, J. (1997). 2-Amino-1-methyl-6phenylimidazo[4,5-b]pyridine increases the numbers of tumors, cystic crypts and aberrant crypt foci in multiple intestinal neoplasia mice. Carcinogenesis, 18 1049-1054.

Stoltzfus, R. J. (2001). Defining iron-deficiency anemia in public health terms: A time for reflection. Journal of Nutrition, 131, 565S-567S.

Su, L. K., Kinzler, K. W., Vogelstein, B., Preisinger, A.C., Moser, A.R., Luongo, C., Gould, K. A. \& Dove, W. F. (1992). Multiple intestinal neoplasia caused by a mutation in the murine homolog of the apc gene. Science, 256, 668-670.

Taddei, S., Virdis, A., Ghiadoni, L., Sudano, I., \& Salvetti, A. (2001). Endothelial dysfunction in hypertension. Journal of Cardiovascular Pharmacology, 48, S11-S14.

Tak, P. P., \& Firestein, G. S. (2001). NF-kB: A rkey role in inflammatory diseases. Journal of Clinical Investigations, 107, 7-11.

Tannenbaum, S. R., Wishnok, J. S., \& Leaf, C. D. (1991). Inhibition of nitrosamine formation by ascorbic acid. American Journal of Clinical Nutrition, 53, 2475-2505.

Tian, S., Simon, I., Moreno, V., Roepman, P., Tabernero, J., Snel, M., van't Veer, L., Salazar, R. Bernards, R., \& Capella, G. (2013). A combined oncogenic pathway signature of BRAF, KRAS and PI3KCA mutation improves colorectal cancer classification and cetuximab treatment prediction. Gut, 62, 540-549.

Toden, S., Bird, A.R., Topping, D. 1, \& Conlon, M.A. (2006). Resistant starch prevents colonic DNA damage induced by high dietary cooked red meat or casein in rats. Cancer Biology \& Therapy, 5, 267-272.

Toyota, M., Ahuja, N., Ohe-Toyota, M., Herman, J. G., Baylin, S. B., \& Issa, J. P. J. (1999). CpC island methylator phenotype in colorectal cancer. Proceedings of the National Academy of Sciences of the United States of America, 96, 8681-8686.

Truswell, A. S. (2009). Problems with red meat in the WCRF2. American Journal of Clinica Nutrition, 89, 1274-1275 (author reply 1275-6).

Tsunoda, T., Takashima, Y., Fujimoto, T., Koyanagi, M., Yoshida, Y., Doi, K., Tanaka, Y., Kuroki, M., Sasazuki, T., \& Shirasawa, S. (2010). Three-dimensionally specific inhibition of DNA repair-related genes by activated KRAS in colon crypt model. Neoplasia, 12, 397-404.

USDA ERS (2009). Red meat and poultry production. Available at: http://ers.usda.gov/ data-products/livestock-meat-domestic-data.aspx\#26154 Last accessed 28.02.2014

Van Breda, S. G., van Agen, E., Engels, L. G., Moonen, E. J., Kleinjans, J. C., \& van Delft, J. H. (2004). Altered vegetable intake affects pivotal carcinogenesis pathways in colon mucosa from adenoma patients and controls. Carcinogenesis, 25, 2207-2216.

Van Es, J. H., Giles, R. H., \& Clevers, H. C. (2001). The many faces of the tumor suppressor gene APC. Experimental Cell Research, 264, 126-134.

Vermeer, I. T., Pachen, D.M., Dallinga, J. W., Kleinjans, J. C., \& van Maanen, J. M. (1998) Volatile N-nitrosamine formation after intake of nitrate at the ADI level in combination with an amine-rich diet. Environmental Health Perspectives, 106 459-463.

Versilovskis, A., \& De Saeger, S. (2010). Sterigmatocystin: Occurrence in foodstuffs and analytical methods - An overview. Molecular Nutrition \& Food Research, 54, $136-147$

Vipperla, K., \& O'Keefe, S. J. (2012). The microbiota and its metabolites in colonic mucosal health and cancer risk. Nutrition Iin Clinical Practice, 27, 624-635.

Walker, P., Rhubart-Berg, P., McKenzie, S., Kelling, K., \& Lawrence, R. S. (2005). Public health implications of meat production and consumption. Public Health Nutrition, 8 348-356.

Wang, C., Zhao, R., Huang, P., Yang, F., Quan, Z., Xu, N., \& Xi, R. (2013). APC loss-induced intestinal tumorigenesis in Drosophila: Roles of Ras in Wnt signaling activation and tumor progression. Developmental Biology, 378, 122-140.

Watanabe, T., Wang, S., Noritake, J., Sato, K., Fukata, M., Takefuji, M., Nakagawa, M., Izumi, N., Akiyama, T., \& Kaibuchi, K. (2004). Interaction with IQGAP1 links APC to Rac1, Cdc42, and actin filaments during cell polarization and migration. Developmental Cell, 4, 871-883.

Westerterp-Plantenga, M. S., Nieuwenhuizen, A., Tome, D., Soenen, S., \& Westerterp, K. R. (2009). Dietary protein, weight loss, and weight maintenance. Annual Review of Nutrition, 29, 21-41.

Williams, P. (2007). Nutritional composition of red meat. Nutrition \&' Dietetics, 64, S113-S119.

Williams, P. G., \& Droulez, V. (2010). Australian red meat consumption - Predominantly lean in response to public health and consumer demand. Food Australia, 62, 87-94.

Wodarz, A., \& Näthke, I. (2007). Cell polarity in development and cancer. Nature Cell Biology, 9, 1016-1024.

WHO (2013). Obesity and overweight fact sheet. Available at: http://www.who.int/ mediacentre/factsheets/fs311/en/ Last accessed: 28.02.2014.

World Cancer Research Fund (2009). Policy and action for cancer prevention: food nutrition and physical activity. Available at. www.dietandcancerreport.org

World Cancer Research Fund/American Institute for Cancer Research (2007). Food, nutrition, physical activity, and the prevention of cancer: A global perspective. Second expert panel report. Washington DC: AICR.

Yamada, K. M., \& Cukierman, E. (2007). Modeling tissue morphogenesis and cancer in 3D. Cell, 130, 601-610. 